\title{
Tyrphostin AG126 exerts neuroprotection in CNS inflammation by a dual mechanism
}

Christiane Menzfeld, $\mathrm{PhD}^{1,2}$, Michael John, $\mathrm{XX}^{3}$, Denise van Rossum, $\mathrm{PhD}^{1,4}$, Tommy Regen, PhD $^{1,5}$, Jörg Scheffel, PhD ${ }^{1,6}$, Hana Janova, MSc ${ }^{1}$, Alexander Götz, $X^{1}{ }^{1}$, Sandra Ribes, PhD ${ }^{1}$, Roland Nau, MSc, MD ${ }^{1}$, Angela Borisch, $\mathrm{XX}^{1}$, Philippe Boutin, BSc ${ }^{1}$, Konstantin Neumann, $\mathbf{P h D}{ }^{7,8}$, Vanessa Bremes, $\mathbf{P h D}^{7}$, Jürgen Wienands, $\mathbf{P h D}^{7}$, Holger M. Reichardt, $\mathrm{PhD}^{7}$, Fred Lühder, $\mathrm{PhD}^{9}$, Denise Tischner, $\mathrm{XX}^{9}$, Vicky Waetzig, $\mathrm{XX}^{10}$, Thomas Herdegen, MD, PhD ${ }^{10}$, Peter Teismann, $\mathbf{P h D}^{11}$, Iain Greig, $\mathbf{P h D}^{11}$, Michael Müller, XX ${ }^{12}$, Tobias Pukrop, MD $^{13}$, Alexander Mildner, PhD $^{1,14}$, Helmut Kettenmann, PhD $^{15}$, Wolfgang Brück, MD ${ }^{1}$, Marco Prinz, MD $^{16}$, Shlomo Rotshenker, MD ${ }^{17}$, Martin S. Weber, MD ${ }^{1,18}$ and Uwe-Karsten Hanisch, PhD $^{{ }^{*}}$

\footnotetext{
${ }^{1}$ Institute of Neuropathology, University of Göttingen, Germany

${ }^{2}$ present address: Department of Physiology and Pathophysiology, Institute of Neuro- and Sensory Physiology, University of Göttingen, Germany

${ }^{3}$ Institute for Inorganic Chemistry, University of Göttingen, Germany

${ }^{4}$ present address: Sartorius-Stedim Biotech GmbH, Göttingen, Germany

${ }^{5}$ Institute of Molecular Medicine, University of Mainz, Mainz, Germany

${ }^{6}$ present address: Department of Dermatology and Allergy, Charité-Universitätsmedizin Berlin, Berlin, Germany

${ }^{7}$ Institute of Cellular and Molecular Immunology, University of Göttingen, Germany

${ }^{8}$ Institut für Klinische Chemie und Pathobiochemie, Technische Universität München, München, Germany

${ }^{9}$ Institute for Multiple Sclerosis Research, University of Göttingen and Gemeinnützige Hertie-Stiftung,

Göttingen, Germany

${ }^{10}$ Institute of Experimental and Clinical Pharmacology, University Clinikum, Kiel, Germany

${ }^{11}$ Institute of Medical Sciences, University of Aberdeen, Scotland, UK

${ }^{12}$ Department of Physiology and Pathophysiology, Institute of Neuro- and Sensory Physiology, University of Göttingen, Germany

${ }^{13}$ Department of Oncology and Haematology, University of Göttingen, Germany

${ }^{14}$ present address: Department of Immunology, Weizmann Institute of Science, Rehovot, Israel.

${ }^{15}$ Cellular Neurosciences, Max Delbrück Center for Molecular Medicine, Berlin, Germany

${ }^{16}$ Institute of Neuropathology \& BIOSS Centre for Biological Signalling Studies, University of Freiburg, Germany

${ }^{17}$ Department of Medical Neurobiology, Hebrew University of Jerusalem, Israel

${ }^{18}$ Department of Neurology, University of Göttingen, Germany
}

Running head: $\quad$ AG126 in autoimmunity and inflammation

*Correspondence: $\quad$ Dr. Uwe-Karsten Hanisch

Institute of Neuropathology, University of Göttingen

Robert-Koch-Straße 40, D-37075 Göttingen

嘼 (+49-551) 396520, 且 (+49-551) 398472

邑 ukhanisch@med.uni-goettingen.de

Manuscript: $\quad 79$ characters in title, 38 characters in running head ; XXX words in Abstract, 9144 words (main text body from Introduction to Discussion), 8/5 figures/in color, 12/1 supplementary figures/table 


\section{ABSTRACT}

Objective: The putative protein tyrosine kinase (PTK) inhibitor tyrphostin AG126 has proven beneficial in various models of inflammatory diseases. Yet molecular targets and cellular mechanisms remained enigmatic.

Methods: Effects of AG126 were investigated in mice with experimental autoimmune encephalomyelitis (EAE), a model for multiple sclerosis, based on clinical scoring, histology and analysis of inflammatory infiltrates. Cellular mechanisms were determined by assays for antigen presentation, $\mathrm{T}$ cell and microglia activation, also involving mouse strains transgenic for a myelin-specific $\mathrm{T}$ cell receptor or with deficiencies in Toll-like receptor (TLR) signaling proteins. Molecular mechanisms and targets of AG126 were identified by a combination of spectroscopic, bio/chemical and cell-based studies.

Results: In EAE, AG126 ameliorates the clinical symptoms, diminishes encephalitogenic Th17 differentiation, reduces inflammatory CNS infiltration as well as microglia activation and attenuates myelin damage. It impedes with T(h17) cell activation and directly inhibits Bruton's tyrosine kinase (BTK), a PTK associating with B cell receptor and TLR signaling. However, BTK inhibition cannot account for the entire activity spectrum. Effects on TLRinduced proinflammatory cytokines in microglia involve AG126 hydrolysis and conversion of its dinitrile side chain to malononitrile (MN). Notably, while liberated MN can subsequently mediate critical AG126 features, full protection in EAE still requires delivery of the intact AG126.

Interpretation: The anti-inflammatory potential of AG126 and especially its interference with TLR signaling rely on a dual mechanism encompassing BTK and a novel MN-sensitive target. Both principles bear great potential for the therapeutic management of disturbed innate and adaptive immune functions. 


\section{INTRODUCTION}

Excessive inflammation can precipitate tissue impairment, up to organ failure with lethal outcome. The CNS is especially vulnerable to dysregulated inflammatory processes often associating with infection, trauma, stroke, neurodegenerative or autoimmune diseases, such as multiple sclerosis (MS), the most common CNS autoimmune disease ${ }^{1,2}$. Strategies have been developed to moderate uncontrolled immune responses ${ }^{2-5}$. Yet some cause serious side effects. In MS, for instance, recently developed treatments aim at specific elements of pathogenesis more effectively and conveniently, but run a risk of opportunistic infections or secondary autoimmunity ${ }^{6-10}$. A search for alternative anti-inflammatory compounds should thus also consider novel targets.

Tyrphostins comprise a class of synthetic protein tyrosine kinase (PTK) inhibitors that were originally developed for cancer treatment ${ }^{11}$. As tyrosine analogues they are designed to interfere with tyrosine phosphorylation in PTK substrates. Tyrphostins could thereby offer more selectivity than PTK inhibitors aiming at the common ATP binding site. In terms of potency, tyrphostins would compete with the rare protein substrates rather than the abundant ATP. Since PTKs are involved in virtually all cellular functions as positive and negative regulators of signaling ${ }^{5}$, tyrphostins also proved beneficial in inflammatory conditions ${ }^{12,13}$.

Tyrphostin AG126 ( $\alpha$-cyano-[3-hydroxy-4-nitro]cinnamonitrile) was found to rescue mice from lethal consequences of bacterial lipopolysaccharide (LPS) administration in a model of septic shock ${ }^{14}$. Subsequent studies confirmed protective actions in various inflammatory disease models ${ }^{15-25}$. We contributed findings regarding CNS complications, showing AG126 interference with microglial reactions to Toll-like receptor (TLR) activation 26-29. Expressed by innate immune cells, such as CNS microglia, TLRs trigger crucial responses to infection and tissue damage, including production of proinflammatory cytokines 
30,31. However, despite its obvious anti-inflammatory potential, the affected PTK activity and the cellular mechanisms of AG126 remained unknown.

Here, we identify Bruton’s tyrosine kinase (BTK) as a target of AG126, a Tec family member known for key roles in B cell receptor (BCR) signaling and adaptive immunity ${ }^{32}$. BTK deficiency causes X-linked agammaglobulinemia, the most common human monogenetic immunodeficiency with extreme susceptibility to infection ${ }^{32}$. On the other hand, BTK inhibition promises clinical success in treatments of lymphoma ${ }^{33,34}$. Since BTK also associates with TLRs ${ }^{35,36}$, further roles emerge for innate immune cells ${ }^{37}$. X-linked immunodeficient (Xid) mice lacking functional BTK present with reduced severity of inflammatory diseases ${ }^{37}$.

We show that AG126 protects mice with experimental autoimmune encephalomyelitis (EAE), a model of MS. It largely interferes with antigen presentation and activation of T cells, especially abrogating a Th17 response. Treatment efficiently attenuates clinical symptoms and myelin damage. We thereby unravel a mechanism with a dual hit on adaptive and innate immune functions that builds on BTK inhibition and on AG126 conversion to malononitrile (MN), as a novel TLR response modifier.

\section{MATERIALS AND METHODS}

\section{Animals}

C57BL/6 and NMRI wildtype (wt) as well as $t \mathrm{r}^{-{ }^{-/}}$, $m y d 88^{-/-}$, trif ${ }^{p s 2}$ and $2 \mathrm{D} 2$ mice (matching the C57BL/6 background) were provided by the Central Animal Facility of the University Medicine Göttingen (UMG) and housed under standard or pathogen-free (SPF) conditions, respectively, with food and water ad libitum ${ }^{38}$. Embryonic $\mathrm{gr}^{+/+}, \mathrm{gr}^{+/-}$and $\mathrm{gr}^{-/-}$mice were obtained from the Institute for Multiple Sclerosis Research (IMSF) Göttingen ${ }^{39}$. Animals were treated according to the guidelines for animal care of the University of Göttingen. 


\section{EAE}

Eight to 12 weeks old female C57BL/6 mice were injected subcutaneously into the flanks with $100 \mu \mathrm{g}$ of myelin oligodendrocyte glycoprotein peptide (MOG $\mathrm{MO}_{35-55}$, PanaTecs) in a PBS emulsion of complete Freund's adjuvant (Sigma, containing $1 \mathrm{mg} / \mathrm{ml}$ of Mycobacterium tuberculosis H37RA, Difco). After immunization and $48 \mathrm{~h}$ later, mice received an intravenous injection of $300 \mathrm{ng}$ pertussis toxin in saline (List). Mice were weighed and scored daily for disease symptoms (see below). Mice were treated with $\alpha$-cyano-[3-hydroxy-4nitro]cinnamonitrile (AG126, Calbiochem), malononitrile (MN) or 3-hydroxy-4nitrobenzaldehyde (BZ, both Sigma) diluted in DMSO (stock solutions adjusted to $50 \mu$ l for intraperitoneal injection) or only with vehicle over 3 to 5 days prior to, upon or following the onset of clinical symptoms (as indicated). At the end of the respective observation period, animals were anesthetized and transcardially perfused with PBS as well as 4\% paraformaldehyde (PFA, Merck, in PBS) for histological examination or only PBS-perfused and sacrificed for tissue sampling, flow-cytometric and functional in vitro analyses.

\section{Clinical scoring}

Clinical scores were assessed daily up to 30 days as follows: 0 , no clinical symptoms; 0.5 , reduced tail tone; 1.0, limp tail, mouse cannot be rotated; 1.5 , mouse can be rotated, turns back on its own; 2.0, mouse cannot rotate back alone; 2.5, paraparesis of one hindlimb; 3.0 paraparesis of both hindlimbs; 3.5, paraparesis of both hind limbs and one forelimb; 4.0, tetraparesis (abort criterion); 5, moribund or death. Animals that had lost more than $20 \%$ of their maximal body weight within $48 \mathrm{~h}$ or that had reached a score of 4 were sacrificed by cervical dislocation and excluded from the experiment.

\section{Cell preparation and cultures}

Microglial cells were prepared from whole brains of wt, $t \operatorname{lr} 4^{-/}$, myd88 ${ }^{-/-}$and trif $^{\text {ps2 }}$ mice (postnatal day 0) and cultured in complete Dulbecco’s modified Eagle’s medium with 10\% fetal calf serum (DMEM/FCS, Invitrogen/Gibco), $100 \mathrm{U} / \mathrm{ml}$ penicillin and $100 \mu \mathrm{g} / \mathrm{ml}$ 
streptomycin (Biochrom) ${ }^{38}$. Brains were freed from contaminating meninges and blood vessels, washed with Hank’s balanced salt solution (Biochrom) and incubated with 2.5\% trypsin (Biochrom) for $10 \mathrm{~min}$ at $37^{\circ} \mathrm{C}$. The reaction was stopped by adding complete medium, supplemented with $0.4 \mathrm{mg} / \mathrm{ml}$ DNAse (CellSystem), followed by incubation at $37^{\circ} \mathrm{C}$ for 5 min. Remaining cell clusters were mechanically separated and the suspension was centrifuged at $200 \mathrm{x}$ g at $4^{\circ} \mathrm{C}$ for $10 \mathrm{~min}$. Cells were resuspended in fresh complete medium and seeded in $75 \mathrm{~cm}^{2}$ culture flasks, which were coated with $100 \mu \mathrm{g} / \mathrm{ml}$ poly-L-lysine (Invitrogen/Gibco) for $30 \mathrm{~min}$ at $\mathrm{RT}$ and rinsed with sterile $\mathrm{ddH}_{2} \mathrm{O}$ just before being used. Cultures were kept in humidified atmosphere with $5 \% \mathrm{CO}_{2}$ at $37^{\circ} \mathrm{C}$. After one day, the cultures were washed 3 times (PBS, Invitrogen/Gibco) and were given fresh complete medium. The medium was changed every other day. After 5 days, microglial proliferation was stimulated by adding complete medium supplemented with 30\% of L929-conditioned cell culture supernatant ${ }^{40}$. After 3 to 5 days, microglia were collected from the astrocytic layer by shaking, washed with complete medium, counted and placed in well plates or dishes. Microglia preparations routinely reached a purity of $>98 \%$, as evaluated by nuclear staining with DAPI, immunocytochemistry for CD11b and Iba1 expression as well as by Griffonia simplicifolia isolectin $\mathrm{B}_{4}\left(\mathrm{ILB}_{4}\right)$ labeling. Routine experiments were performed in 96-well plates with $100 \mu \mathrm{l}$ of medium for $18 \mathrm{~h}$.

For the preparation of $g r^{+/}, g r^{-/}$and $g r^{+/+}$(wt) microglia, pregnant mice were sacrificed by cervical dislocation. The skin was disinfected and removed on the ventral side. Uteri were opened, embryos separated from the placenta and transferred separately to Petri dishes filled with Hank's buffered saline solution (HBSS) solution. Arms were taken for genotyping and brains processed individually for cell cultures to ensure genotypic homogeneity. Cells were finally plated in 96- and 12-well plates, or on cover slips in 12-well plates or in Petri dishes (34 mm) at densities of $1.5 \times 10^{4}, 2 \times 10^{5}$ or $10^{6}$ cells per well/dish, respectively. 
Human Ramos B cells positive for IgM were cultivated to a density of $2 \times 10^{5}$ to $2 \times 10^{6}$ cells $/ \mathrm{ml}$ at $37^{\circ} \mathrm{C}, 5 \% \mathrm{CO}_{2}$ in RPMI1640 medium with $10 \%$ FCS. Cells were collected by centrifugation at $4^{\circ} \mathrm{C}$, pellets washed in PBS and cells concentrated to $6 \times 10^{6}$ cells $/ \mathrm{ml}$ in serum-free medium. $500 \mu \mathrm{l}$ of cell suspension were transferred to reaction tubes.

Splenocytes were isolated and T cells were purified by MACS negative selection as described ${ }^{41}$.

\section{Microglial experiments}

Microglia were stimulated with $\mathrm{Pam}_{3} \mathrm{CSK}_{4}$ ((S)-[2,3-bis(palmitoyloxy)-2(2-RS)-propyl]-Npalmitoyl-(R)-Cys-(S)-Ser-(S)-Lys4-OH3HCl), poly(I:C) (polyinosinic-polycytidylic acid), LPS (Re-LPS, Escherichia coli, serotype R515), flagellin (Salmonella typimurium strain 14028), MALP-2 (S-[2,3-bis(palmityloxy)-(2R)-propyl-cysteinyl-GNNDESNISFKEK]), poly(U) (polyuridylic acid potassium salt), CpG ODN 2395 (synthetic oligodesoxynucleotide TCGTCGTTTTCGGCGCGCGCCG, all from Apotech) and poly(A:U) (polyadenylic acidpolyuridylic acid, Sigma), prepared as stock solutions and kept at $-20^{\circ} \mathrm{C}$ until use., Microglial cells were also treated with malononitrile (MN), 3-hydroxy-4-nitro-benzaldehyde (BZ), dexamethasone, DL-noradrenaline hydrochloride, phentolamine methanesulfonate, propranolol (Sigma), AG126, AG9, AG17, AG18, AG43, AG82, AG1288, LFM-A13, Cpd A (2-((4-Acetoxyphenyl)-2-chloro-N-methyl) ethylammonium chloride), 1-[(4,5-bis(4methoxyphenyl-2-thiazoyl)carbonyl]-4-methylpiperazine or 4-[(5-difluoromethyl-3-phenyl)4-isoxazolyl]benzenesulfonamide (Calbiochem /Merck) as agonists, antagonists or inhibitors either alone or in combination. Stock solutions were prepared in DMSO, water or PBS (as instructed by the manufacturer), stored at $-20^{\circ} \mathrm{C}$ and used within recommended periods upon purchase. Tyrphostins were handled in the dark. Treatment of cells with inhibitors also involved respective pre-incubations (as outlined in the text)

\section{Splenocyte recall assays}


For primary proliferative responses, spleen cells were directly isolated from AG126-treated mice with MOG $35-55$-induced EAE, cultured and challenged with $\mathrm{MOG}_{35-55}$ antigen for $72 \mathrm{~h}$, pulsed with $1 \mu \mathrm{Ci}$ of $\left[{ }^{3} \mathrm{H}\right]$ thymidine, harvested $16 \mathrm{~h}$ later and analyzed for $\left[{ }^{3} \mathrm{H}\right]$ incorporation. Culture supernatants were collected for cytokine analyses by ELISA. In another approach, T cells from 2D2 mice (transgenic for a MOG-specific TCR) and T cell-free splenocytes from wt mice were isolated using MACS-based separation procedures (with positive and negative selection for $\mathrm{CD}^{+}$cells, Miltenyi Biotec). Preparations of the T cells $\left(2 \times 10^{4}\right)$ and splenocytes (5x10 , used as APCs) were individually incubated with AG126 (100 $\mu \mathrm{M}, 1 \mathrm{~h})$, combined and stimulated with MOG $35-55$ peptide, either in the continued presence of AG126 or without. Combinatory recall experiments thereby considered T cell-APC mixtures in which only one or both cell types had a pretreatment or where the treatment covered the entire stimulation period. Supernatants were finally analyzed by ELISA.

\section{B cell stimulation assay}

To activate BCR signaling, Ramos cells were stimulated with goat-anti-human IgM-specific $(\mathrm{H}+\mathrm{L}) \mathrm{F}(\mathrm{ab})_{2}$ fragments $\left(10 \mu \mathrm{g} / \mathrm{ml}\right.$, Jackson Immunoresearch) for 1 to $3 \mathrm{~min}$ at $37^{\circ} \mathrm{C}$. The cell suspension was centrifuged (1000xg, 2 min, $\left.4^{\circ} \mathrm{C}\right)$, medium was removed and cells were lysed in $100 \mu \mathrm{l}$ of lysis buffer (50 mM Tris, ph 8.0, $150 \mathrm{mM} \mathrm{NaCl,} 5 \mathrm{mM} \mathrm{NaF}, 0.5 \%$ NP-40, $1 \mathrm{mM}$ protease inhibitor $\mathrm{Na}_{3} \mathrm{VO}_{4}$ ). Lysates were centrifuged (20,000xg, $10 \mathrm{~min}$ ), supernatants were heated for $5 \mathrm{~min}$ at $95^{\circ} \mathrm{C}$ in the presence of $4 \mathrm{x}$ SDS-sample buffer $(250 \mathrm{mM}$ Tris/ $\mathrm{HCl}$, pH 6.8, 200 mM DTT, 40\% glycerol, 8\% SDS, 0.05\% bromophenol blue) and stored at $-20^{\circ} \mathrm{C}$ until immunoblot analysis.

\section{Cell viability}

The WST-1 cell assay was used to determine cell viability. This colorimetric method is based on the cleavage of the tetrazolium salt WST-1 (Roche) by the mitochondrial succinatetetrazolium reductase (part of the respiratory chain) of viable cells which forms a soluble dye (formazan). After respective stimulations, cells received fresh medium with WST-1 reagent 
and were incubated at $37^{\circ} \mathrm{C}$ for $3 \mathrm{~h}$. The color reaction was measured in a microplate reader (Model 680 or iMark, BioRad) at $450 \mathrm{~nm}$ with $655 \mathrm{~nm}$ as reference.

\section{Flow cytometry}

Detection of cell surface and intracellular antigens as well as incorporated myelin by flow cytometry followed protocols described previously ${ }^{42,43}$. To avoid nonspecific binding of antibodies, Fc receptors were blocked using anti-CD16/CD32 antibody (clone 2.4G2, BD Pharmingen). Cells were processed for flow cytometry using a panel of fluorochromeconjugated antibodies: CD3-FITC (clone 145-2C11), CD11b-APC (clone M1/70, both from eBioscience), CD45R/B220-PerCP (clone RA3-6B2), Ly6C-PE (clone AL-21), Ly6G (clone 1A8, all from BD Biosciences), MHCI-AlexaFluor (clone KH114 and 34-1-2S) and MHCIIAlexaFluor (clone KH116, both from BioLegend). For staining of microglia, also ILB 4 -FITC (Vector Laboratories) was used. Following treatments of microglial cultures with agonists and antagonists or incubation under control conditions, cells were rinsed with culture medium and detached from the culture dish by addition of $300 \mu$ l of $0.05 \%$ trypsin, $0.02 \%$ EDTA (w/v) (all Biochrom) in $\mathrm{PBS}$ for $3 \mathrm{~min}$ at $37^{\circ} \mathrm{C}, 5 \% \mathrm{CO}_{2}$. The reaction was stopped by adding 600 $\mu \mathrm{l}$ of medium. Cells were scratched off, transferred to $2 \mathrm{ml}$ reaction tubes, washed with medium and centrifuged at $800 \mathrm{xg}$ for $12 \mathrm{~min}$ at $4^{\circ} \mathrm{C}$. The supernatant was discarded and cells were washed in PBS or FACS buffer (2\% FCS, 0.01 mM EDTA, 0.1\% $\mathrm{NaN}_{3}$ in PBS, pH 8.0). Incubations with antibodies or $\mathrm{ILB}_{4}$ were performed for 20 and $30 \mathrm{~min}$, respectively, on ice in the dark, followed by rinses, collection by centrifugation and resuspension. For detection of intracellular antigens, cells were fixed and permeabilized with Cytofix/Cytoperm (BD Biosciences). Subsequent incubations were performed in PBS containing 2\% FCS and 0.1\% $\operatorname{saponin}^{38,43}$.

CNS-infiltrating cells were isolated as described ${ }^{44}$. Preparations were incubated in HBSS containing collagenase and DNAse for $1 \mathrm{~h}$. Cells were isolated on a Percoll gradient and washed twice before FACS staining. Proinflammatory T, Th1 and Th17 cell 
differentiation was evaluated by staining with dye-labeled antibodies against surface CD3 (Pharmingen) as well as intracellular IFN $\gamma$ and IL-17 (eBioscience).

For blood cell analyses, 3 to 4 drops of whole blood were collected into an excess volume (1-2 ml) of FACS buffer and mixed by shaking. Samples were centrifuged for $10 \mathrm{~min}$ at $200 \mathrm{xg}$ at $4^{\circ} \mathrm{C}$. Supernatants discarded. Cells were resuspended by vortexing and $100 \mu \mathrm{l}$ of FACS buffer containing the fluorescence-coupled antibodies was added. Samples were again vortexed and incubated at $4^{\circ} \mathrm{C}$ in the dark for $30 \mathrm{~min}$. After staining, samples were vortexed and $1 \mathrm{ml}$ of lysis buffer was directly added to the cells. Samples were again vortexed and incubated for 10 min at room temperature in the dark. Afterwards, the tubes were filled with FACS buffer, centrifuged as above and the supernatants were discarded. Washing was repeated once with FACS buffer. Cells were finally resuspended in $300 \mu \mathrm{l}$ FACS buffer, stored at $4^{\circ} \mathrm{C}$ in the dark and analyzed within $48 \mathrm{~h}$.

To quantify myelin phagocytosis by microglia, myelin was purified from isolated brains as described (van Rossum et al. 2008; Regen et al. 2011). Purified myelin was labeled with FITC using an EZ-Label protein labeling kit (Pierce). FITC-labeled myelin $(10 \mu \mathrm{g} / \mathrm{ml})$ was added to the cultures for 30 or 120 min. Excess myelin was removed by rinsing twice with medium and once with PBS. Harvested cells were then stained with CD11b-APC, washed, resuspended in FACS buffer and analyzed as described above.

Cells were acquired on FACSCalibur or LSRFortessa flow cytometers (BD Biosciences). Data were analyzed using FlowJo (TreeStar) and WinMDI software.

\section{Mitochondrial analysis}

Changes in the mitochondrial electrochemical potential gradient $(\Delta \psi)$ were analyzed using a mitochondria staining kit (Sigma). Microglia seeded in 96-well plate were stimulated with TLR ligands in the presence or absence of AG12 for $18 \mathrm{~h}$ and JC-1 staining was performed according to the manufacturer's instruction. Mitochondria with an intact membrane potential were revealed by the JC- 1 dye as red fluorescent aggregates within the mitochondrial matrix. 
A disrupted membrane potential was indicated when the monomeric dye was dispersed throughout the cell with green fluorescence. Valinomycin was employed for control treatment according to the manual. Besides a microscopic inspection, red and green fluorescence intensities were measured in a Safire UV-VIS spectrophotometer (Tecan), using 490/530 and 525/590 $\mathrm{nm}$ as excitation/emission wavelengths and XFLUOR4 version 4.40 software.

\section{Cytokine measurements}

Recombinant mouse IFN $\gamma$, IL-17A and IL-17E were obtained in carrier-free form (R\&D Systems). Cultures supernatants or plasma samples were analyzed by commercial ELISA for CCL2, CCL3, CCL5, CXCL1, IFN $\gamma$, IL-6 and IL-17 (DuoSet ELISA Development Kits, R\&D Systems), TNF $\alpha$ (BioLegend) and total IL-12p40 (covering also monomeric p40, eBioscience). Absorbance was measured at $450 \mathrm{~nm}$ (with $540 \mathrm{~nm}$ reference) using an iMark microplate reader (Bio-Rad).

\section{Proteins and kinase activity}

Activation or activities of BTK, p38 ${ }^{\mathrm{MAPK}}, \mathrm{p} 42 / 44^{\mathrm{MAPK}}, \mathrm{JNK}, \mathrm{PLC} \gamma 2$ and NFkBp65 were determined by ELISAs, arrays and immunoblots relying on sequence- and phosphorylation site-specific antibodies as well as recombinant protein references (Cell Signaling Technology, R\&D Systems, Invitrogen). NFאBp65 activation was also analyzed by immunocytochemistry. The phosphorylation status of signaling molecules in microglia was analyzed by PathScan phospho-NFkBp65 (Ser 536), phospho-p38 ${ }^{\text {MAPK }}$ (Thr 180/Tyr 182), phospho-p44/42 ${ }^{\text {MAPK }}$ (ERK 1/2, Thr 202/Tyr 204) and phospho-JNK (Thr 183/Tyr 185) ELISA Kits (Cell Signaling Technology) according to the instructions. TLR-stimulated microglia and control cells were washed with ice-cold PBS and incubated with cell lysis buffer containing $1 \mathrm{mM}$ of phenylmethylsulfonylfluoride for $5 \mathrm{~min}$. Scraped cells were transferred into $1.5 \mathrm{ml}$ reaction tubes, sonificated for $5 \mathrm{~s}$ at 65\% intensity (Sonicator sonoplus HD 2070MS72, Bandelin) and centrifuged at 10,000xg for $10 \mathrm{~min}$. Supernatants were taken and cleared cellular lysates were stored at $-80^{\circ} \mathrm{C}$. The whole procedure was carried out on ice. The color reaction was 
measured in a microplate reader (Model 680, BioRad). To ensure equal protein amounts in the samples, GAPDH immunoblot and total protein content analyses were performed (see below). To analyze induced phosphorylation of MAPKs and further serine/threonine kinases a Human Phospho-MAPK Proteome Profiler Array was used which is also suitable for mouse study, based on a list confirmed analytes (R\&D systems). Reactions were carried out according to the manufacturer's instructions and using a Chemidoc Imager for detection (Biorad).

BTK activity was measured by detecting the phosphorylation of tyrosine residues in a library of tyrosine-containing peptides with random sequences as coated on a 96-well plate of a pan-PTK assay (Sigma). The reaction buffer contained ATP, $\mathrm{Mg}^{2+}$ as well as $\mathrm{Mn}^{2+}$ and the reaction was initiated by addition of recombinant BTK (PV3363, Invitrogen) at 10 to 100 $\mathrm{ng} / \mathrm{ml}$ for various periods of time up to $60 \mathrm{~min}$. The BTK was diluted to appropriate concentrations in enzyme dilution buffer (20 mM Tris, $\mathrm{pH}$ 7.5, containing $0.05 \%$ Triton $\mathrm{R} X-$ 100, $10 \%$ glycerol, $0.1 \mathrm{mg} / \mathrm{ml}$ BSA, $2 \mathrm{mM}$ dithiothreitol and $0.5 \mathrm{mM} \mathrm{Na}_{3} \mathrm{VO}_{4}$ ). A monoclonal anti-phospho-tyrosine antibody conjugated with HRP served the conversion of a chromogenic substrate. Assay conditions were optimized and applied to determine inhibition by AG126 and LFM-A13 at 50 to $500 \mu \mathrm{M}$ with $50 \mathrm{ng} / \mathrm{ml}$ of BTK over a 30 min reaction time, as outlined in the main text.

Immunoblot detection of BTK was performed on microglial and $\mathrm{T}$ cell lysates. Microglia were taken from the standard cultures. T cell preparations reached $98 \%$ purity by MACS isolation. Equal amounts of protein were separated by SDS-PAGE under non-reducing conditions along with Precision PlusProteinWesternC Standards using a Mini-Protean 3 Cell, followed by a transfer to immunoblot PVDF membranes using a Semi-Dry Transfer Cell (all BioRad). Blots were blocked with 5\% skimmed milk and subsequently developed with an anti-BTK antibody (raised in rabbits against the N-terminus, ABIN1031284, Antikörper online/ProSci Inc.) and a goat-anti-rabbit IgG-HRP (A9169, Sigma), followed by ECL reaction and detection (CPS-1-60, Sigma) on LumiFilm (Roche). Analyses of JNK and 
phospho-JNK proteins were performed as described ${ }^{45}$. Detection of GAPDH involved a respective mouse antibody (Imgenex) and a goat-anti-mouse IgG-HRP conjugate (Sigma). Analyses of B cell lysates was performed with rabbit-anti-phospho-PLC 2 (Y759) and rabbitanti-PLCy2 (Cell Signaling Technology) as well as a mouse-anti-phospho-Tyr (clone 4G10, Upstate), following the instructions of the manufacturers) and using ECL reaction for visualization in a ChemiLux Imager (Intas). For reprobing, membranes were washed and incubated for $30 \mathrm{~min}$ at $50^{\circ} \mathrm{C}$ with stripping buffer (68.5 mM Tris, $\mathrm{pH} \mathrm{6.8,} \mathrm{2 \%} \mathrm{SDS,} 100 \mathrm{mM}$ $\square$ mercaptoethanol).

Protein content of cellular lysates was determined using a bicinchoninic acid (BCA) assay (Pierce/Thermo Scientific). The color reaction was measured at $540 \mathrm{~nm}$ in a microplate reader (Model 680, BioRad).

\section{PCR analyses}

Polymerase chain reactions (PCR) were performed on RNA isolated from $8 \times 10^{6}$ microglial cells using a RNA purification kit (RNeasy Mini Kit, Qiagen). Samples of $1 \mu \mathrm{g}$ RNA were treated with $1 \mu \mathrm{l}$ of DNaseI (Roche) and $1 \mu \mathrm{l}$ RNase Inhibitor (Promega) in $14 \mu \mathrm{l}$ RNase free ddH2O for $30 \mathrm{~min}$ at $37^{\circ} \mathrm{C}$ and for another $10 \mathrm{~min}$ at $70^{\circ} \mathrm{C}$. Thereafter, RNA was transcribed into cDNA using $8 \mu \mathrm{l}$ of oligo-dT primers (Roche), $8 \mu \mathrm{l}$ x buffer, $4 \mu \mathrm{l}$ of $0.1 \mathrm{M}$ DTT, $4 \mu \mathrm{l}$ SuperScript II Reverse Transkriptase (provided in a kit from Invitrogen) and $4 \mu \mathrm{dNTPs}$ (PeqLab) for $60 \mathrm{~min}$ at $37^{\circ} \mathrm{C}$. The reverse transcriptase was inactivated at $95^{\circ} \mathrm{C}$ for $15 \mathrm{~min}$. PCR was performed with PCR buffer, $1.5 \mathrm{mM} \mathrm{MgCl2,} 0.25 \mathrm{mM}$ dNTPs, $1 \mathrm{pmol} / \mu \mathrm{l}$ of forward and reverse primers and $1 \mathrm{U}$ Taq polymerase (Promega). The PCR program included steps at $94^{\circ} \mathrm{C}$ for $5 \mathrm{~min}, 28$ or 30 cycles at $94^{\circ} \mathrm{C}$ for $30 \mathrm{~s}, 55.5^{\circ} \mathrm{C}$ for $45 \mathrm{~s}, 72^{\circ} \mathrm{C}$ for $45 \mathrm{~s}$ and finally $5 \mathrm{~min}$ at $74^{\circ} \mathrm{C}$. The following forward (fw) and reverse (rv) primers (MWG) were used: TLR1 (fw 5' CAA ACG CAA ACC TTA CCA GAG TG, rv 3’ GAG ATT CGG GGT CTT CTT TTT CC), TLR2 (fw 5’ AAA ATG TCG TTC AAG GAG, rv 3’ TTG CTG AAG AGG ACT GTT), TLR3 (fw 5’ ACT TGC TAT CTT GGA TGC, rv 3’ AGT TCT TCA CTT 
CGC AAC), TLR4 (fw 5’ TCC CTG ATG ACA TTC CTT CTT, rv 3’ TGA GCC ACA TTG AGT TTC TTT A), TLR5 (fw 5’ CGC CTC CAT TCT TCA TTC CG, rv 3’ CCT TCA GTG TCC CAA ACA GTC G), TLR6 (fw 5’ CTT ACT CGG AGA CAG CAC TGA AGTC, rv 3’ GCA GGT GGG TGA CAT CTT TAG G), TLR7 (fw 5’ TGA CTC TCT TCT CCT CCA, rv 3’ GCT TCC AGG TCT AAT CTG), TLR8 (fw 5’ CTG TCC AAG GTG TTA CAA TGC TCC, rv 3’ TTG AGA GAG GTT TCC GAA GAC G) and TLR9 (fw 5’ GGT GTG GAA CAT CAT TCT, rv 3’ ATA CGG TTG GAG ATC AAG). PCR products were separated in a 1.5\% agarose gel and stained with ethidium bromide.

\section{Spectral and spectroscopic analyses}

Characterization of chemical stability and identification of conversion products of tyrphostins was performed by recording UV/VIS spectra as well as applying nuclear magnetic resonance (NMR) spectroscopy methods to the compounds in different solvent environments. Tyrphostins AG18, AG82 and AG126 (50 mM in DMSO, diluted to $100 \mu \mathrm{M}$ in medium) were incubated in 96-well plates with or without microglia at $37^{\circ} \mathrm{C}, 5 \% \mathrm{CO}_{2}$ for different time periods. Afterwards, absorbance spectra (230 to $500 \mathrm{~nm}$, at $2 \mathrm{~nm}$ intervals) were recorded at room temperature in a 384-well flat bottom transparent UV-permeable plates (Greiner), using a Safire spectrometer (Tecan, see also above). Spectra were normalized to the absorbance peak at $560 \mathrm{~nm}$ of phenol red in medium. Characteristic absorbance maxima of AG18, AG82 and AG126 (449, 470 and 435 nm, respectively) were plotted against time.

For NMR spectroscopy, samples of 1 or $5 \mathrm{mg}$ of AG126 were prepared in $600 \mu \mathrm{l}$ absolute DMSO-d6, $600 \mu \mathrm{l}$ DMSO- $d 6$ containing $\mathrm{H}_{2} \mathrm{O}$ and a mixture of $500 \mu \mathrm{l}$ of DMSO-d6 and $100 \mu \mathrm{l} \mathrm{D}_{2} \mathrm{O}$. The solutions were transferred to 5mm NMR tubes. All NMR spectra were recorded on a Avance $500 \mathrm{MHz}$ NMR spectrometer (Bruker) at $25^{\circ} \mathrm{C}$. Samples were monitored over a period of 21 days. ${ }^{1} \mathrm{H}$ NMR spectra were recorded using 20 scans and $2.75 \mathrm{~s}$ acquisition. The solvent HDO peak was calibrated to $4.70 \mathrm{ppm}$. 
Due to its low intrinsic sensitivity ${ }^{13} \mathrm{C}$ NMR spectra were run on the $5 \mathrm{mg}$ samples with 2048 scans in typically $1.5 \mathrm{~h}$. The ${ }^{13} \mathrm{C}$ resonances were calibrated indirectly using $\Xi$ (TMS) $=0.25145020$ and assigned using the 2D heteronuclear single quantum correlation (HSQC) and heteronuclear multiple bond correlation (HMQC) experiments, optimized for ${ }^{1} \mathrm{~J}_{\mathrm{CH}}=145 \mathrm{~Hz}$ and ${ }^{2 / 3} \mathrm{~J}_{\mathrm{CH}}=7 \mathrm{~Hz}$, respectively. The $2 \mathrm{D}$ spectra were recorded using a spectral widths of $11 \mathrm{ppm}\left({ }^{1} \mathrm{H}\right)$ and $110 \mathrm{ppm}\left({ }^{13} \mathrm{C}\right), 16$ or 32 scans and $1024\left({ }^{1} \mathrm{H}\right)$ x $256\left({ }^{13} \mathrm{C}\right)$ complex time domain data points in typically 4 or $8 \mathrm{~h}$.

2D Diffusion-ordered (DOSY) spectra were recorded using the ledbpgp2s sequence with $(\delta / 2=2 \mathrm{~ms})$ bipolar z gradients ramped from 1 to $50 \mathrm{G} / \mathrm{cm}$, a diffusion delay $(\Delta)$ of 100 ms and longitudinal eddy current delay of $10 \mathrm{~ms}$. The data matrix had a size of $8 \mathrm{k}\left({ }^{1} \mathrm{H}, 0.68 \mathrm{~s}\right.$ acquisition) x 64 (diffusion dimension) and was recorded with 8 scans in typically $1 \mathrm{~h}$.

\section{Histology and immunocytochemistry}

Mice were anesthetized and perfused through the left cardial ventricle with PBS followed by 4\% PFA, in PBS, pH 7.3. The vertebral canal, head, and specimens of liver and spleen were prepared and postfixed in $4 \%$ PFA at $4^{\circ} \mathrm{C}$. After a rinse in PBS, spinal cord and brain were dissected, followed by dehydration and paraffin embedding of tissues in a Leica TP 1020 Tissue Processor. Blocks of embedded tissue were sliced into $1 \mu \mathrm{m}$ coronal sections with a Leica SM 2000 R sliding microtome and transferred to coated object slides (Superfrost Plus microscope slides, Thermo Scientific). Slides were dried and stored until further processing. Deparaffinization was performed with xylene. Subsequently, tissues sections were consecutively transferred to isopropanol (in $\left(\mathrm{dH}_{2} \mathrm{O}\right)$ of decreasing concentrations.

Haematoxylin-Eosin (H\&E) staining was performed with Mayer’s hemalaun solution (Merck, 5 min). Sections were washed with $\mathrm{dH}_{2} \mathrm{O}$ and differentiated with $1 \% \mathrm{HCl}$ in $90 \%$ isoopropyl alcohol. Tissue was blued by rinsing slides under tap water. Sections were then incubated in $1 \%$ eosin solution for 5 min (1\% eosin G, Merck, in $70 \%$ isopropyl alcohol, stirred and filtered, with 10 drops of glacial acetic acid being added before use). Afterwards, 
slides were rinsed in $\mathrm{dH}_{2} \mathrm{O}$, dehydrated by an alcohol series as well as xylene and mounted using DePex mounting medium (Serva).

Luxol Fast Blue/Periodic Acid Schiff (LFB/PAS) staining was used to detect demyelinized tissue areas. Sections were incubated in LFB solution $(0.1 \% \mathrm{w} / \mathrm{v}$ LFB in $96 \%$ ethanol, $0.05 \%$ acetic acid) overnight at $60^{\circ} \mathrm{C}$, washed shortly in $90 \%$ ethanol, dipped in 0.05\% lithium carbonate (in $\mathrm{dH}_{2} \mathrm{O}$, Roth), differentiated in $70 \%$ alcohol and rinsed in $\mathrm{dH}_{2} \mathrm{O}$. For PAS staining, sections were incubated for 5 min in $1 \%$ periodic acid (in $\mathrm{dH}_{2} \mathrm{O}$, Merck), rinsed for 5 min under tap water and shortly washed in $\mathrm{dH}_{2} \mathrm{O}$. Sections were incubated for 20 min in Schiff reagent (Sigma), rinsed under tap water for 5 min, kept in hemalun solution (Merck) for 2 min and rinsed again with $\mathrm{dH}_{2} \mathrm{O}$. For differentiation, sections were incubated in 1\% $\mathrm{HCl} /$ alcohol (as above) and blued under tap water. The sections were finally dehydrated in an increasing alcohol series, incubated in xylene and embedded in synthetic mounting medium (DePeX, Serva).

Bielschowsky silver staining was performed to determine axonal density. Sections were incubated in $20 \%$ silver nitrate solution (in $\mathrm{ddH}_{2} \mathrm{O}$, Roth) for 20 min and stored in $\mathrm{dH}_{2} \mathrm{O}$. Ammonium hydroxide solution (32\%, Merck) was added while stirring, until precipitates disappeared. Further drops were added and slides were incubated in the dark for 15 min. Subsequently, slides were stored in $\mathrm{ddH}_{2} \mathrm{O}$ containing a few drops of ammonium hydroxide. Developer solution (6\% formalin in $\mathrm{dH}_{2} \mathrm{O}, 0.4 \%$ citric acid, $0.05 \%$ nitric acid) was stirred into the silver nitrate/ammonium hydroxide solution. The reaction was stopped by $\mathrm{dH}_{2} \mathrm{O}$ addition, slides were incubated in $2 \%$ sodium thiosulfate (in $\mathrm{dH}_{2} \mathrm{O}$ ) for 2 min, rinsed under water, dehydrated in an alcohol series and xylene and embedded in DePeX mounting medium.

Macrophages and microglia were detected by staining tissues for the calcium-binding protein ionized calcium binding adaptor molecule 1 (Iba1). Slides were pretreated with citrate buffer (10 mM citric acid, adjusted to $\mathrm{pH} 6.0$ with $\mathrm{NaOH}$, both Merck) $6 \mathrm{x}$ for $3 \mathrm{~min}$ and transferred to PBS. Endogenous peroxidase was blocked with $3 \% \mathrm{H}_{2} \mathrm{O}_{2}$ in PBS for 20 min. 
Slides were rinsed in PBS and blocked in normal serum solution (5\% serum, 5\% skimmed milk powder) for $1 \mathrm{~h}$ at room temperature. In general, normal serum originated from the animal species of the secondary antibody as applied to the respective staining. Afterwards, sections were incubated in the primary antibody solution of rabbit anti-Iba1 (Wako, 1:400 diluted in $50 \%$ blocking solution in PBS) overnight at $4^{\circ} \mathrm{C}$. Sections were washed $3 \times 5$ min with PBS and incubated with biotinylated donkey-anti-rabbit IgG as the secondary antibody (Amersham, 1:200 in 50\% blocking solution in PBS) for 1 hour. Sections were again washed in PBS for 3 x 5 min and incubated with an avidin-peroxidase-complex solution (Sigma, 1:1000 in 50\% blocking solution, Sigma) at RT for $1 \mathrm{~h}$. Sections were washed again with PBS and staining was developed with diaminobenzidin (DAB, Sigma), followed by rinses in $\mathrm{dH}_{2} \mathrm{O}$. Sections were incubated for $3 \mathrm{~min}$ with Mayer's hemalum solution (Merck) for counterstaining, dehydrated and embedded as for H\&E staining.

Staining of CD3, as a T cell co-receptor, followed the procedure as used for Iba1 detection, using normal goat serum as a blocking reagent as well as rat anti-CD3 and biotinylated goat anti-rat-IgG as primary and secondary antibodies (Serotec, 1:100, and Amersham, 1:200, respectively).

Translocation of phospho-NFkBp65 to the nucleus was analyzed for TLR-stimulated and control microglia cells seeded on cover slips and fixed for 15 min with PFA (4\% in PBS). After washing with PBS, cells were incubated in permeabilization and blocking solution (0.1\% Triton, 10\% FCS in PBS), followed by incubation with rabbit-anti-phospho-NF (Ser536) antibody (Cell Signaling Technology, 1:500 in 10\% FCS) overnight at $4^{\circ} \mathrm{C}$. Cells were washed with PBS and incubated with the secondary antibody, an anti-rabbit-IgG-Cy3 (1:400 in 10\% FCS in PBS) for 30 min in the dark. Cells were washed again and counterstained with the microglia marker ILB4-FITC (1:200 in 10\% FCS in PBS) for 2 h. For nuclear staining, washed cells were incubated with 4'-6-diamidino-2-phenylindole (DAPI, 
1:1000 in PBS, Roche) for 10 min. Cells were washed, dipped in $\mathrm{ddH}_{2} \mathrm{O}$ and mounted with fluorescence mounting medium (Dako) on an slide.

Staining of BTK in microglia was similarly carried out on microglia in vitro, following fixation with PFA and blocking with $2 \%$ bovine serum albumin, $5 \%$ normal goat serum in PBS containing $0.5 \%$ Triton X-100. The anti-BTK antibody (as shown above) and a sheepanti-rabbit-IgG F(ab')2-Cy3 (Sigma, 1:100) were used as primary and secondary antibodies, combined with ILB4-FITC and DAPI for microglial surface and nuclear staining. Fluorescence signals were scanned for each dye channel at 4 optical planes with $1 \mu \mathrm{m}$ interval and z stacks were combined to generate overlay images.

Staining was analyzed and images were taken with a BX51 microscope equipped with a DP71 camera and Cell F 2006 as well as analySIS Software (Olympus). Fluorescence images were taken with the Olympus microscope as also equipped with a U-RFL-T lamp device (Olympus) and with a Biorevo BZ-9000 microscope with integrated software (Keyence).

\section{Statistics}

Statistics were performed with the Student's t and Mann-Whitney U tests. Differences were considered significant with $\mathrm{p}<0.05$, individual values being indicated in the figures.

\section{RESULTS}

\section{AG126 treatment is beneficial in EAE}

Since AG126 offers protection in various models of inflammatory diseases, including those of the CNS ${ }^{27}$, we addressed its potential to ameliorate clinical symptoms and to mitigate tissue damage in mice with EAE. EAE can be induced in various animal species, by varying protocols and with different antigen preparations to reflect distinct clinical courses, neuropathological features and inflammatory conditions ${ }^{46} . \mathrm{MOG}_{35-55}$-based EAE, as used 
here, largely develops by activation of $\mathrm{T}$ cells, while macrophages/microglia have critical contributions ${ }^{47,48}$. We found that AG126 can interfere with both.

Upon immunization, clinical signs of paralysis developed (Fig 1A). With their onset around day 12, one group of animals received three daily intraperitoneal injections of AG126, which significantly improved their performance. Clinical scores stagnated even after terminating AG126 delivery. On day 22, animals were sacrificed and spinal cord tissues were analyzed by histology.

Mice with EAE and vehicle treatment revealed a massive infiltration of immune cells, namely $\mathrm{CD}^{+} \mathrm{T}$ cells, along with overt signs of white matter (myelin) damage, axonal injury and microglial activation (Fig 1B, Supplementary Fig 1). In contrast, mice that had received AG126 presented with reduced immune infiltrates, less pronounced lesions and preservation of white matter structures (Fig 1C).

We then modified the treatment schedule by administering AG126 either before or after clinical symptoms had manifested (Fig S2A). While preventive treatment resulted in a delayed disease onset and late treatment abrogated a further score increase, both application windows resulted only in partial white matter protection (Fig S2B).

Thus, even a transient AG126 treatment can reduce EAE severity when initiated with the appearance of clinical signs. Part of the beneficial effect may rely on the impediment of T cell recruitment. We had already reported on protective AG126 effects in models of CNS infection where it interfered with leukocyte influx ${ }^{27,28}$.

\section{AG126 interferes with Th17 differentiation of encephalitogenic T cells}

To dissect the mechanism by which AG126 interfered with EAE, immunized mice were repeatedly treated with AG126 or vehicle (as in Fig 1) and sacrificed for tissue sampling. Splenocytes were isolated and re-challenged ex vivo with $\mathrm{MOG}_{35-55}$ antigen. Cells from AG126-treated mice revealed reduced proliferation, attenuated IL-2 and a virtually abolished 
IL-17 production, suggesting a major impact on Th17 cells (Fig 2A and B). In contrast, IFN $\gamma$ was not much affected, suggesting that the Th1 subset was spared. Flow-cytometric analyses of CNS tissue samples confirmed a reduced infiltration by T(h17) cells following AG126 treatment (Fig 2C), while circulating leukocyte populations were not altered (Supplementary Fig 2C).

\section{AG126 impedes a successful antigen presentation}

To address the main cellular target of AG126, we employed T cells from the MOG-specific T cell receptor (TCR)-transgenic 2D2 mouse for in vitro activation with $\mathrm{MOG}_{35-55}$ peptide in the presence of wt splenocytes as antigen-presenting cells (APCs) ${ }^{49}$. Even though not fully suitable to study IL-17 regulation per se, this model was used to investigate AG126-mediated immunosuppression at cellular level. In fact, upon antigen re-challenge, AG126 impressively abrogated the release of IL-2, IL-6 (as a surrogate of a potentially Th17-promoting reaction) and IFN $\gamma$ (Fig 2D).

In a second step, we treated purified 2D2 T cell and wt APC preparations with AG126 separately, thereafter combined them and determined the response to a MOG $35-55$ challenge. Despite the only short pretreatment, AG126 attenuated the IL-2 release and efficiently suppressed the induction of IL-6 and IFN $\gamma$, especially when APCs were pretreated (Fig 2D). We conclude that APCs and their subsequent interaction with T cells represent a major target of AG126 and that this provides the immunological basis for its clinical benefit.

\section{AG126 suppresses microglia activation independently of its effect on Th17 development}

AG126 treatment also attenuated the EAE-associated microglia/macrophage activation. We investigated whether this effect would occur secondary to the interference with Th17 development. 
IL-17 is a critical inflammatory cytokine in the pathogenesis of autoimmune diseases, such as MS. Its receptor $\mathrm{IL}-17 \mathrm{R}$ is also expressed on microglia ${ }^{50}$. However, in vitro stimulation of microglia with IL-17A (the prototypic family member) and IL-17E did not cause much of a response in terms of inducing proinflammatory cytokines and chemokines which are otherwise readily triggered upon appropriate activation ${ }^{51}$ (Supplementary Table 1).

In vivo, microglia are under the influence of a host of factors, especially upon tissue impairment. TLRs, in particular, can sense not only microbial agents, but also a variety of damage-released molecules. Accordingly, TLR activation drives microglial responses also in non-infectious situations and participates in neurodegenerative as well as autoimmune processes ${ }^{51,52}$. We thus also determined IL-17 effects on TLR agonist-induced release activities, but observed only marginal alterations. We concluded that, in addition to its influence via IL-17, AG126 could directly act on microglia.

\section{AG126 has a complex influence on TLR agonist-induced microglial cytokines}

We had previously noticed that AG126 impedes microglial TLR signaling ${ }^{27}$. Using this system, we sought to further decipher the mechanism of AG126 action by identifying the immediate target.

TLR activation in microglia induced the production of a spectrum of cytokines and chemokines with important roles in immunoregulation (Supplementary Fig 3). Next, we determined effects of AG126 on selected TLR agonists (Fig 3A). AG126 had discrete and partially biphasic influences on responses to $\mathrm{Pam}_{3} \mathrm{CSK}_{4}$ (TLR1/2), poly(I:C) (TLR3), MALP2 (TLR6/2) and CpG ODN (TLR9). It mostly inhibited release of TNF $\alpha$, IL-6, CCL2 or CCL5, especially when applied at $>50 \mu \mathrm{M}$.

Notably, profiles differed for LPS (TLR4). AG126 caused only moderate release inhibition, whereas production of factors, like CXCL1, was even augmented. Consequently, AG126 influences were not globally suppressive and involved more than a single target. 


\section{AG126 acts on TLR signaling mainly through the MyD88-dependent pathway}

While most TLRs signal through myeloid differentiation primary response gene 88 (MyD88), TLR3 relies on Toll-receptor-associated activator of interferon (TRIF, TICAM-1), and TLR4 recruits both signaling adaptors ${ }^{30}$. To narrow down on targets in these pathways, we determined AG126 influences on the induction of factors that critically depend on MyD88 or TRIF and compared their regulation in microglia with deficiencies in these signaling proteins.

TNF $\alpha$ and CXCL1 inductions depend on MyD88. They are only partially impaired by TRIF absence in trif ${ }^{\text {ps2 }}$ microglia ${ }^{38}$. Accordingly, TLR activation failed to trigger release in myd88 ${ }^{-/}$microglia, but was effective in trif ${ }^{p s 2}$ cells (Supplementary Fig 4). AG126 presence then affected TNF $\alpha$ and CXCL1 release in wildtype (wt) and trif ${ }^{\text {ps2 }}$ cells, with inhibition or enhancement depending on the TLR (as in Fig 3A).

IFN $\beta$ production requires TRIF. It was induced by LPS in wt but not in trif ${ }^{p s 2}$ cells (Fig 3B and C). On the other hand, AG126 did not change the respective IFN $\beta$ levels in wt or myd88 $8^{-/-}$microglia.

The findings suggested that AG126 affects TLR signaling along the MyD88 route. To confirm the involvement of this pathway we determined the impact of AG126 on additional TLR-controlled functions, such as microglial surface expression of major histocompatibility class (MHC) I for antigen presentation. Its induction is selective for MHCI (no induction of MHCII) and depends on TRIF ${ }^{38}$. Correspondingly, activation of TRIF via TLR3 by poly(I:C) and of TRIF as well as MyD88 via TLR4 by LPS resulted in MHCI upregulation (Fig 4A). AG126 caused only a minor effect on the TLR3 $\rightarrow$ TRIF-induced MHCI level, whereas it had some impact (at $100 \mu \mathrm{M}$ ) on the TLR4 $\rightarrow$ TRIF/MyD88-driven expression. This pattern suggested that AG126 could spare responses when they are solely TRIF-mediated, while affecting them in a cooperative signaling involving both pathways. 
Microglia readily phagocytose myelin debris, a process which is attributed to a subset of cells where it is suppressed by TLR activation in a MyD88-dependent manner ${ }^{38}$. AG126 rescued myelin clearing activity from LPS inhibition, further pointing to the sensitivity of MyD88 signaling (Fig 4B and C).

\section{AG126 does not exert a global effect on MyD88-controlled signaling}

AG126 exerted only selective effects on MyD88 downstream signaling. Following TLR activation, nuclear translocation and phosphorylation of NFאBp65, JNK, p38 and ERK, respectively, were not affected in general (Supplementary Fig 5A-C), but using a phosphoprotein array with MAPK subtype resolution, we found AG126 to suppress TLRtriggered phosphorylation of $\mathrm{p} 38 \alpha^{\mathrm{MAPK}}$ and ERK2/p42 ${ }^{\mathrm{MAPK}}$ (Supplementary Fig 5D). Since the overall impact on NFאB and MAPK activation was limited, the putative AG126-sensitive PTK would associate with the TLR/interleukin-1 receptor (IL-1R) $\rightarrow$ MyD88 signaling route, rather than mediating it.

\section{AG126 can directly inhibit BTK, which is expressed in microglia but not in $\mathrm{T}$ cells}

We had previously defined criteria for a potential target of AG126 ${ }^{29}$, which eventually led our search to BTK, a PTK also associating with TLRs and MyD88 ${ }^{53}$. To test the hypothesis, we compared effects on BTK for AG126 and LFM-A13, an established BTK inhibitor ${ }^{35,53}$. Both blocked the enzymatic activity of recombinant BTK (Fig 5A). Both inhibited phosphorylation of phospholipase C (PLC) $\gamma 2$ at Tyr759 in BCR-stimulated Ramos cells-a typical BTK activity (Fig 5B).

We confirmed the expression of BTK in microglia. We detected mRNA and protein (Supplementary Fig 6), with a subcellular localization already reported for other cells ${ }^{36}$. T cells studied in parallel were devoid of any detectable BTK levels, further adding to the notion that AG126 exerted effects on T(h17) cells in EAE indirectly via APC functions. 
Although these experiments identified BTK as an AG126-sensitive PTK, AG126 and LFM-A13 differently influenced microglial cyto/chemokine inductions (Fig 5C). This suggested that BTK is a shared but not the only target.

\section{Alternative mechanisms based on the AG126 structure can be ruled out}

Besides BTK, AG126 could act on closely related PTKs. At mRNA level, we found Tec as the family name-giving kinase to be expressed in microglia, but not other members, like Itk, Rlk or Bmx. On the other hand, some tyrphostins were reported for activities exceeding PTK inhibition. An antioxidant action as described for AG490 ${ }^{54}$ was excluded since AG126 lacks a quinone-like body.

Tyrphostins A9, AG10 and AG18 interfere with the respiratory chain coupling to oxidative phosphorylation and affect signaling ${ }^{55,56}$. The uncoupling potential of AG126 was assessed using the fluorescent dye JC-1 for microglial staining and ratiometric analysis of the integrity of their mitochondrial membrane potential $(\Delta \psi)$. AG126 did not cause overt impairment, neither alone nor in combination with TLR1/2 activation, whereas control cells treated with valinomycin indicated $\Delta \psi$ collapse (Supplementary Fig 7).

AG126 and noradrenaline are both tyrosine derivatives. They also have similar effects on TLR2-triggered release profiles in microglia. We thus considered agonistic activity of AG126 for adrenoreceptors (AR). However, while the $\beta_{1} / \beta_{2}$-adrenergic antagonist propranolol abolished the $\beta_{2}$-AR-dependent suppressive effect of noradrenaline on TLR1/2-triggered TNF $\alpha$ and CXCL1 release, it had no influence on the AG126-mediated inhibition (Supplementary Fig 8). Similarly, phentolamine methanesulfonate (PAMS) did not rescue release from AG126 inhibition, ruling out any $\alpha_{1} / \alpha_{2}$-AR role.

The PTK inhibitor genistein is also a phytoestrogen, and we had shown that the plantderived compound A could deliver anti-inflammatory effects by serving as a non-steroidal 
ligand of glucocorticoid receptors (GR) ${ }^{57}$. As a modifier of TLR-triggered cyto-/chemokine production in microglia, it compared to dexamethasone and-notably-to AG126. Intriguingly, it also mimicked the peculiar increase in TLR4-induced CXCL1 levels. To evaluate GR involvement, we compared TNF $\alpha$ and CXCL1 induction in cells with GR deficiency (Supplementary Fig 9). While dexamethasone effects were impaired in heterozygous and lost in homozygous GR knockout microglia, AG126 developed influences on TLR1/2-induced release as it did in wt cells. Together the findings excluded such atypical mechanisms.

AG126 was claimed to influence enzymes and adhesion molecules that organize for inflammatory mediators and cell recruitment, including IL-1R-associated kinase (IRAK), ICAM-1, cyclooxygenase (COX) 2 and inducible nitric oxide synthase (iNOS) 12,15,16,18,22,25,5864. COX2 is readily induced in TLR-stimulated microglia ${ }^{43}$, but we ruled out that its suppression would play a major role, e.g. via autocrine loops (Supplementary Fig 10). Furthermore, we had shown that AG126 decreases NO synthesis ${ }^{29}$. Yet interference with the sluggish NO production will not alter rapid cytokine release. None of these parameters could conclusively tell or give hints to an ultimate alternative target.

\section{NMR spectroscopy reveals fragmentation products of AG126}

Spectral HPLC analyses indicated the disappearance of AG126 from microglial cultures with time. To verify a suspected chemical instability we recorded changes in absorption spectra of AG126 and, for comparison, AG18 and AG82 in culture medium over 24 h. Normalized for the phenol red peak in medium (560 nm), fading of signals at 435, 449 and $470 \mathrm{~nm}$ revealed degradation, especially for AG18 and AG82. Presence of cells even facilitated the process.

AG126 conversion was systematically followed by NMR spectroscopy (Supplementary Fig 11). AG126 dissolved in absolute DMSO was stable, showing trace amounts of putative photodimerization products only after weeks. In contrast, AG126 
dissolved in DMSO with residual water content $\left(\mathrm{DMSO}_{\mathrm{aq}}\right)$ slowly revealed the appearance of a -CHO group, which was subsequently oxidized to a carboxylic acid. The conversion rate increased when AG126 was prepared in a mixture of $\mathrm{DMSO}_{\mathrm{aq}}$ and $\mathrm{D}_{2} \mathrm{O}$ (1:4). Thus, AG126 undergoes degradation under conditions applied in studies of its biological activities.

3-Hydroxy-4-nitrobenzaldehyde (BZ) was then identified as a hydrolytic product by recording ${ }^{1} \mathrm{H}$ and ${ }^{13} \mathrm{C}$ NMR spectra of AG126 in different solvents, assigning signals to individual atoms in the structure. This was confirmed by analysis of a commercial BZ sample (Supplementary Fig 11). Stoichiometrically, AG126 decomposition to BZ ultimately also generates malononitrile (MN, Fig 6A).

\section{AG126 is a precursor of MN as a microglia-modulating compound}

Next we evaluated individual contributions of BZ and MN to the activity spectrum of AG126, comparing their influences on TLR-induced cyto-/chemokines. Exemplified for CCL2, MN inhibited TLR1/2- and TLR6/2-mediated inductions like AG126 did, while both spared the release under TLR4 stimulation (Fig 6B). Summarizing data from entire profiles, AG126 effects correlated best with those of MN (Fig 6C). Even though direct detection of MN by spectroscopic methods was hampered, $\mathrm{MN}$ as a degradation product could mimic biological effects of AG126.

\section{MN has no effect on BTK and only restricted impact on MyD88 downstream signaling}

In contrast to AG126, neither MN nor BZ inhibited the enzyme activity of BTK (Fig 5A). On the other hand, and like AG126, MN had little influence on MyD88 downstream signaling via NFאB and MAPKs, except for some inhibition of p38 and ERK phosphorylation. From these observations and from its chemical structure, it became clear that MN would influence certain TLR-induced activities, but in a PTK/BTK-independent fashion. 


\section{AG126-related tyrphostins share microglia-modulating activity}

If MN generation underlies some of the release-affecting properties of AG126, related tyrphostins with a dinitrile residue should have similar effects. We tested a battery of such compounds (Supplementary Fig 12). Although variation in the kinetics of MN generation, the primary effects as PTK inhibitors or contributions of the aromatic breakdown product must be expected, several had AG126-like influences, including the striking upregulation of TLR4triggered CXCL1.

\section{Effects of AG126 and MN can superimpose}

Combination of BTK-dependent and -independent effects of AG126 and MN could explain the complex and partially biphasic regulation of certain cyto-/chemokine inductions (Fig 3A). Influences may overlay to determine the net inhibition—or even augmentation. In fact, BTK deficiency can cause also enhanced production of some TLR-induced cytokines, such as in B cells ${ }^{36}$. We thus also considered actions of AG126/MN at two targets in EAE.

\section{Intact AG126 is required for protection in EAE}

Whereas MN mimicked AG126 effects on microglial activities, it failed to be effective in EAE. Treatment with MN neither reduced the clinical score nor the size of white matter lesions (Fig 7A and B). The number of $\mathrm{CD}^{+} \mathrm{T}$ cells found in CNS tissue remained unchanged (Fig 7C). Microglia activation was not different when compared to the control situation of EAE without treatment (Fig 7D). Similarly, BZ also did not affect the clinical course and histological outcome.

AG126-treated mice revealed a larger spleen, probably as a sign of reduced cell egress (Fig 7E). Interestingly, the individual performance of these four experimental groups in EAE was not adequately reflected by the levels of circulating cytokines, as exemplified by TNF $\alpha$, IL-6 and IL-12 (Fig 7F). Some peripheral effects of MN-as indicated by reduced levels of 
certain factors-did obviously not translate into CNS consequences. Lower serum cytokine levels in general did not correlate with better clinical presentation (Fig 7G).

Taking together, neither of the two daughter products was able to replace AG126 for ameliorating EAE. Full efficacy in vivo depended on the parent structure. Protective potential of AG126 may thus primarily rely on BTK inhibition and interference with APC-T cell interactions. Via BTK, AG126 may influence signaling cascades in diverse cell types. As to TLR-triggered responses, it could have additional effects beyond those of the breakdown products. Essential conclusions on the mechanisms are depicted in a scheme (Fig 8).

\section{DISCUSSION}

\section{AG126 protects mice with EAE and suppresses their Th17 and microglia responses}

AG126 treatment alleviated functional deteriorations, preserved white matter structures and reduced CNS infiltration by T cells. AG126 particularly reduced the activity of Th17 cells, which are responsible for substantial tissue impairment in autoimmune diseases ${ }^{50}$. Recall experiments with antigen on splenocytes from AG126-treated mice revealed a dramatic decline of IL-17 production. Yet we also demonstrate that an IL-17 drop alone cannot account for attenuated microglia activation — matching data by others ${ }^{50}$ —and that AG126 rather acts directly on these cells. It interferes with their TLR $\rightarrow$ MyD88 signaling, a pathway with importance in EAE ${ }^{47}$. Ideally, combined effects on T(h17) cells and microglia could be traced to a single PTK. We reveal BTK as a primary target of AG126.

\section{BTK inhibition by AG126 can affect B and T cell functions directly and indirectly}

BTK is important for B cell function and protection against infection ${ }^{32}$, whereas therapeutic inhibition shows impressive effects on B cell lymphomas ${ }^{33,34}$. On the other hand, BTK- 
dysfunctional Xid mice are less affected by inflammatory diseases ${ }^{37}$. Proposing BTK as a target of AG126 in EAE agrees with these findings.

In B cells, IL-17 production depends on BTK ${ }^{65}$. However, B cells do not play a major role in our paradigm ${ }^{44}$, and the BTK-IL-17 link may not operate in Th17 cells. T cells do not express BTK 66,67 . We could also not detect it in our preparations, excluding direct AG126 $\rightarrow$ BTK actions. Our experiments on T cells from 2D2 mice indicate that AG126 preferentially blocks T(h17) cell activation by APCs.

Moreover, the relative sparing of Th1 responses by AG126 in our EAE mice resembles the dominant Th1 profiles upon infection in human agammaglobulinemia ${ }^{68}$. In BTK-deficient mice, this skewing was assigned to altered T cell priming by APCs ${ }^{67}$.

\section{BTK inhibition by AG126 can affect microglial functions}

BTK has also implications in myeloid cells and even prognostic value in myelomas ${ }^{37,69-71}$. Notably, BTK integrates in TLR signaling, although functions vary by cell types ${ }^{72}$.

Reports on a rescue of mice from endotoxic shock and on LPS-induced responses already point to an AG126 target within TLR signaling ${ }^{14,27}$. We nominated features for a candidate in microglia, i.e. constitutive expression, TLR association, a position upstream of stress- and mitogen-activated kinases (SAPK/MAPK, or even MEK) as well as a link to the control of the intracellular calcium concentration $\left(\left[\mathrm{Ca}^{2+}\right]_{\mathrm{i}}\right)^{27,29,73}$.

BTK fulfils these criteria. BTK activates PLC $\gamma 2$ in the BCR signalosome, mobilizing calcium and activating protein kinase C (PKC), RasGRP, NFאB or NFAT. BTK binds TLR4, MyD88 and IRAK1, phosphorylates TLR3 and MyD88 adapter-like protein (MAL/TIRAP), the sorting adapter bridging MyD88 to TLR2 or TLR4, and supports NFאBp56 transactivation 35,53,74,75. Association with intracellular MHCII, a novel mechanism of TLR4 signaling control in macrophages and dendritic cells ${ }^{76}$, may enable BTK to distinctly affect TLR4 signaling in microglial subpopulations ${ }^{43,77,78}$. 


\section{BTK inhibition by AG126 can affect TLR signaling upon infection and damage}

Previous reports on AG126 in TLR-mediated responses mostly referred to infections. In contrast, efficacy of AG126 in EAE and other non-infectious conditions will relate to TLR/BTK functions as driven by endogenous agonists. TLRs sense both pathogen- as well as damage-associated molecular patterns (PAMPs, DAMPs) and integrate them for fighting infection or supporting repair, also in microglia ${ }^{51}$. PAMPs derive from conserved structural motifs in microbes. DAMPs are classified as a collection of disparate, self-derived molecules acquiring the meaning of danger signals by non-physiological release or modification upon cell impairment and tissue destruction. They orchestrate a (presumably protective) sterile inflammation ${ }^{30,31}$, but occasionally also fuel harmful cascades ${ }^{79-81}$. AG126 seems to impede damage-driven mechanisms-with positive net outcome not only in EAE, but also in models of pleurisy, arthritis, pancreatitis or multiorgan failure ${ }^{15,17-19}$.

\section{AG126 manipulates cellular functions also via a BTK-independent mechanism}

As PTK inhibitors, tyrphostins deliberately compete with protein substrates, while being noncompetitive for ATP. Yet some are ATP- or bisubstrate-competitive ${ }^{11}$. Nevertheless, the focus on kinase inhibitor selectivity has been revisited. Actions on multiple kinome targets are no longer seen as disadvantageous ${ }^{5}$. We demonstrate that AG126 is a PTK inhibitor as well as the precursor for an additional signaling-affecting molecule.

Certain tyrphostins affect signaling and transcription independently of any (known) PTK 82. They act as antioxidants, mitochondrial uncouplers or inhibitors of G proteins and GTPdependent enzymes ${ }^{54,55,83,84}$. Unconventional activities even cover stimulation of MAPKs and gene induction. Based on structure, AG126 is unlikely to scavenge reactive oxygen species or to inhibit GTPases, but it was reported to reduce the mitochondrial membrane potential and to increase NO-sensitive genes in certain cell models ${ }^{55,82}$. 
To identify non-PTK mechanisms of AG126, we considered adrenergic and steroid-like effects, reasoned from its relation to tyrosine and similarities in modifying TLR-induced functions of microglia. However, pharmacological and knockout approaches excluded such actions. Neither did we obtain unequivocal evidence for uncoupling activity.

Our systematic search unraveled conversion of the AG126 side residue to MN. MN develops autarchy by phenocopying influences on microglial cyto/chemokine production in the absence of any BTK block. Interestingly, presence of two CN groups in tyrphostins correlated with kinase-independent transcriptional effects in a monocytic cell line ${ }^{82}$, while instability of selected tyrphostins caused delayed increases in inhibitory activity ${ }^{85}$. We had speculated on an intracellular 'depot' or interruption of critical signaling events to explain sustained effects of AG126-as a seemingly competitive inhibitor-despite of discontinued presence ${ }^{27}$. The paradox resolves in the light of a two-compounds-two-targets mechanism that has also potential for other tyrphostins and beyond.

\section{AG126 and MN exert dual influences mainly on the MyD88 pathway}

Like BTK, any additional target of AG126/MN would contribute to the MyD88-conveyed signaling, rather than dominating it. AG126/MN impacts differ with the TLR member, and the pattern of effects on cytokines, MHCI as well as phagocytosis in wt, myd88 ${ }^{-/-}$and trif $f^{p s 2}$ microglia point to a predominant manipulation of MyD88 signaling, which leaves the TRIF route largely intact. TLRX/2 challenges obey to AG126/MN, since they exclusively rely on MyD88, whereas responses to TLR4 and TLR3 agonists escape AG126 control, as long as they are solely carried by TRIF. This notion matches previous findings ${ }^{26,27,86}$. Yet we did not observe a general interception of MyD88 downstream events at NFkB, p38, ERK or JNK levels - a finding corroborated by other reports on AG126 ${ }^{15}$ and its relative AG556 ${ }^{12}$, in which actual mechanisms remained obscure. Furthermore, the weak impact of AG126 (MN) 
on TNF $\alpha$ or the intriguing release enhancement for CXCL1 under TLR4 do not fit with a global block of MyD88 signal flow. Both factors mandatorily depend on MyD88 ${ }^{38}$.

\section{AG126/MN may affect lipid (messenger) or energy metabolism and calcium regulation}

MN derivatives were employed in anti-trypanosoma treatment ${ }^{87}$ but nothing is known about biological effects of MN itself. MN may impede metabolic reactions using related molecules as a substrate, inhibitor or regulator. Malonyl-CoA is an intermediate in the cytosolic biosynthesis of long-chained fatty acids and regulates their shuttle into mitochondria for degradation. Malondialdehyde is an oxidative stress marker. Increased blood and tissue levels occur in inflammation, artherosclerosis, diabetes, neurodegenerative diseases and MS ${ }^{88-90}$. It may form Schiff-base adducts with proteins and advanced lipoxidation end products. Proinflammatory consequences in lymphocytes involve $\mathrm{NF \kappa B}, \mathrm{p}^{38^{\mathrm{MAPK}}}$ as well as PKC signaling and cover induction of CCL2, IL-6, ICAM-1 and COX2, among others ${ }^{88}$. Malonate inhibits mitochondrial succinate dehydrogenase (complex II) activity-thereby blocking the citric acid cycle.

AG126/MN had no effects on basal or TLR-enhanced WST-1 conversion, which is catalyzed by the mitochondrial succinate-tetrazolium reductase system, but search for MNexploited mechanisms may still focus on mitochondrial respiration, calcium regulation and connections to inflammatory signaling ${ }^{91,92}$. We reported that AG126 abolishes a TLR(4)elicited elevation of $\left[\mathrm{Ca}^{2+}\right]_{i}$ in microglia, interfering with $\mathrm{NO}$ and cytokine synthesis ${ }^{29,73}$. AG126 also lowered the basal $\left[\mathrm{Ca}^{2+}\right]_{\mathrm{i}}$, agreeing with an impact on a constitutive calcium regulator. Others confirmed $\left[\mathrm{Ca}^{2+}\right]_{\mathrm{i}}$ as a part of TLR4 signaling ${ }^{93}$. The situation resembles the role taken by BTK in BCR $\rightarrow$ PLC $\gamma 2$ signaling. Yet MN would not act on BTK, and BTKPLC $\gamma 2$ interactions in macrophage-like cells may differ from those in B cells ${ }^{93}$. 
The fact that AG126-but not $\mathrm{MN}$ and BZ-protected mice with EAE can be interpreted in two ways. AG126 may escape early hydrolysis by binding to a carrier or insertion into membranes, acting from there on nearby targets, namely BTK. Alternatively, AG126 conversion may lead to additional products which complement the activity spectrum.

BTK reveals a critical participation in CNS autoimmune diseases, in addition to its prominent role in B cell functionality. While AG126 is shown to inhibit BTK, its follow up action through a breakdown product does not only serve as an example for other tyrphostins. It may consciously inspire the development of multi-target drugs. The MN-sensitive signaling element would thereby deserve attention as it determines critical outflows of TLR activation.

Dissection of PTK-dependent and -independent principles of tyrphostin actions and identification of novel targets in TLR signaling potentially offer treatment alternatives in (neuro)inflammatory disorders and cancer.

\section{ACKNOWLEDGEMENTS}

The authors thank Elke Pralle, Susanne Kiecke and Caroline Jaß (University of Göttingen) for excellent technical assistance and Dr. Bernd-Reiner Paulke (Fraunhofer Institute for Applied Polymer Research, Potsdam, Germany) for discussion. This work was supported by grants of the State of Lower Saxony-Israel Research Cooperation (ZN 2035, UKH, SR), the German Research Council (DFG, SFB/TRR43, UKH, HK, HR and WB; FOR1336, MP, UKH) and Parkinson UK (K-1001, IG, PT, UKH). MSW is supported by the Else Kröner Fresenius Stiftung (A69/2010), the DFG (WE 3547/4-1), the US National Multiple Sclerosis Society (NMSS; PP 1660) and the ProFutura Program of the University of Göttingen.

\section{AUTHOR CONTRIBUTIONS}


CM, HK, SRo and UKH initiated and designed the study. CM and UKH wrote the manuscript, with HK, MP, MSW, SRo, TP and WB participating in its editing. MJ contributed the parts of chemical and structural analyses. DT, FL, HR and MSW participated in experiments on EAE, T cell functions and the role of GR. Signaling pathway analyses concerning JNK, BTK and BCR were also organized by JW, KN, TH, VB and VW. MP provided knockout mouse models. Histology was performed with the help of WB. Structurefunction relations of tyrphostins were addressed with IG and PT. All other experiments and analyses were performed and assisted by AB, AG, AM, CM, DvR, HJ, JS, MM, MSW, PB, RN, SRi, TR and UKH.

\section{COMPETING INTERESTS}

Authors do not have conflicts of interest.

\section{REFERENCES}

1. Perry VH, Cunningham C, Holmes C. Systemic infections and inflammation affect chronic neurodegeneration. Nat Rev Immunol. 2007; 7:161-167

2. Murray PJ, Smale ST. Restraint of inflammatory signaling by interdependent strata of negative regulatory pathways. Nat Immunol. 2012; 13:916-924

3. McGeer PL, McGeer EG. NSAIDs and Alzheimer disease: epidemiological, animal model and clinical studies. Neurobiol Aging. 2007; 28:639-647

4. Schweingruber N, Reichardt SD, Luhder F et al. Mechanisms of glucocorticoids in the control of neuroinflammation. J Neuroendocrinol. 2012; 24:174-182

5. Ghoreschi K, Laurence A, O'Shea JJ. Selectivity and therapeutic inhibition of kinases: to be or not to be? Nat Immunol. 2009; 10:356-360 
6. Langer-Gould A, Atlas SW, Green AJ et al. Progressive multifocal

leukoencephalopathy in a patient treated with natalizumab. N Engl J Med. 2005; 353:375-381

7. Coles AJ, Wing M, Smith S et al. Pulsed monoclonal antibody treatment and autoimmune thyroid disease in multiple sclerosis. Lancet. 1999; 354:16911695

8. Cossburn M, Pace AA, Jones J et al. Autoimmune disease after alemtuzumab treatment for multiple sclerosis in a multicenter cohort. Neurology. 2011; $77: 573-579$

9. Weber MS, Menge T, Lehmann-Horn K et al. Current treatment strategies for multiple sclerosis - efficacy versus neurological adverse effects. Curr Pharm Des. 2012; $18: 209-219$

10. Brück W, Gold R, Lund BT et al. Therapeutic Decisions in Multiple Sclerosis: Moving Beyond Efficacy. JAMA Neurol. 2013;

11. Levitzki A, Mishani E. Tyrphostins and other tyrosine kinase inhibitors. Annu Rev Biochem. 2006; 75:93-109

12. Brenner T, Poradosu E, Soffer D et al. Suppression of experimental autoimmune encephalomyelitis by tyrphostin AG-556. Exp Neurol. 1998; 154:489-498

13. George J, Barshack I, Goldberg I et al. The effect of early and late treatment with the tyrphostin AG-556 on the progression of experimental autoimmune myocarditis. Exp Mol Pathol. 2004; 76:234-241

14. Novogrodsky A, Vanichkin A, Patya M et al. Prevention of lipopolysaccharideinduced lethal toxicity by tyrosine kinase inhibitors. Science. 1994; 264:13191322 
15. Balachandra S, Genovese T, Mazzon E et al. Inhibition of tyrosine-kinase-mediated cellular signaling by tyrphostins AG 126 and AG556 modulates murine experimental acute pancreatitis. Surgery. 2005; 138:913-923

16. McDonald M, Abdelrahman M, Cuzzocrea S et al. Tyrphostin reduces the organ injury in haemorrhagic shock: role of inducible nitric oxide synthase. Resuscitation. 2003; 58:349-361

17. Dugo L, Chatterjee PK, Mazzon E et al. The tyrosine kinase inhibitor tyrphostin AG 126 reduces the multiple organ failure induced by zymosan in the rat. Intensive Care Med. 2002; 28:775-788

18. Cuzzocrea S, McDonald MC, Mazzon E et al. The tyrosine kinase inhibitor tyrphostin AG126 reduces the development of acute and chronic inflammation. Am J Pathol. 2000; 157:145-158

19. Cuzzocrea S, McDonald MC, Mazzon E et al. The tyrosine kinase inhibitor tyrphostin AG 126 reduced the development of colitis in the rat. Lab Invest. 2000; 80:1439-1453

20. Chatterjee PK, Patel NS, Kvale EO et al. The tyrosine kinase inhibitor tyrphostin AG126 reduces renal ischemia/reperfusion injury in the rat. Kidney Int. 2003; 64:1605-1619

21. Lopez-Talavera JC, Levitzki A, Martinez M et al. Tyrosine kinase inhibition ameliorates the hyperdynamic state and decreases nitric oxide production in cirrhotic rats with portal hypertension and ascites. J Clin Invest. 1997; 100:664-670

22. Marzocco S, Mazzon E, Pinto A et al. Tyrphostin AG 126 reduces intestinal ischemiareperfusion injury in the rat. Naunyn Schmiedebergs Arch Pharmacol. 2006; $372: 362-373$ 
23. Mijovic JE, Zakar T, Zaragoza DB et al. Tyrphostins inhibit lipopolysaccharide induced preterm labor in mice. J Perinat Med. 2002; 30:297-300

24. Moore BA, Turler A, Pezzone MA et al. Tyrphostin AG 126 inhibits development of postoperative ileus induced by surgical manipulation of murine colon. Am J Physiol Gastrointest Liver Physiol. 2004; 286:G214-G224

25. Ruetten H, Thiemermann C. Effects of tyrphostins and genistein on the circulatory failure and organ dysfunction caused by endotoxin in the rat: a possible role for protein tyrosine kinase. Br J Pharmacol. 1997; 122:59-70

26. Prinz M, Kann O, Draheim HJ et al. Microglial activation by components of grampositive and -negative bacteria: distinct and common routes to the induction of ion channels and cytokines. J Neuropathol Exp Neurol. 1999; 58:1078-1089

27. Hanisch UK, Prinz M, Angstwurm K et al. The protein tyrosine kinase inhibitor AG126 prevents the massive microglial cytokine induction by pneumococcal cell walls. Eur J Immunol. 2001; 31:2104-2115

28. Angstwurm K, Hanisch UK, Gassemi T et al. Tyrosine kinase inhibition reduces inflammation in the acute stage of experimental pneumococcal meningitis. Infect Immun. 2004; 72:3294-3298

29. Kann O, Hoffmann A, Schumann RR et al. The tyrosine kinase inhibitor AG126 restores receptor signaling and blocks release functions in activated microglia (brain macrophages) by preventing a chronic rise in the intracellular calcium level. J Neurochem. 2004; 90:513-525

30. Kawai T, Akira S. The role of pattern-recognition receptors in innate immunity: update on Toll-like receptors. Nat Immunol. 2010; 11:373-384

31. Zhang X, Mosser DM. Macrophage activation by endogenous danger signals. J Pathol. 2008; 214:161-178 
32. Khan WN. Colonel Bruton's kinase defined the molecular basis of X-linked agammaglobulinemia, the first primary immunodeficiency. J Immunol. 2012; $188: 2933-2935$

33. Wang ML, Rule S, Martin P et al. Targeting BTK with ibrutinib in relapsed or refractory mantle-cell lymphoma. N Engl J Med. 2013; 369:507-516

34. Byrd JC, Furman RR, Coutre SE et al. Targeting BTK with ibrutinib in relapsed chronic lymphocytic leukemia. N Engl J Med. 2013; 369:32-42

35. Jefferies CA, Doyle S, Brunner C et al. Bruton's tyrosine kinase is a Toll/interleukin-1 receptor domain-binding protein that participates in nuclear factor kappaB activation by Toll-like receptor 4. J Biol Chem. 2003; 278:26258-26264

36. Mohamed AJ, Yu L, Backesjo CM et al. Bruton's tyrosine kinase (Btk): function, regulation, and transformation with special emphasis on the $\mathrm{PH}$ domain. Immunol Rev. 2009; 228:58-73

37. Mangla A, Khare A, Vineeth V et al. Pleiotropic consequences of Bruton tyrosine kinase deficiency in myeloid lineages lead to poor inflammatory responses. Blood. 2004; 104:1191-1197

38. Regen T, van RD, Scheffel J et al. CD14 and TRIF govern distinct responsiveness and responses in mouse microglial TLR4 challenges by structural variants of LPS. Brain Behav Immun. 2011; 25:957-970

39. Wang D, Muller N, McPherson KG et al. Glucocorticoids engage different signal transduction pathways to induce apoptosis in thymocytes and mature T cells. J Immunol. 2006; 176:1695-1702

40. Pukrop T, Dehgani F, Han-Ning C et al. Microglia promote colonization of brain tissue by breast cancer cells in a Wnt-dependent way. Glia. 2010; 58:14771489 
41. Lehmann-Horn K, Schleich E, Hertzenberg D et al. Anti-CD20 B-cell depletion enhances monocyte reactivity in neuroimmunological disorders. J Neuroinflammation. 2011; 8:146

42. van Rossum D, Hilbert S, Strassenburg S et al. Myelin-phagocytosing macrophages in isolated sciatic and optic nerves reveal a unique reactive phenotype. Glia. 2008; 56:271-283

43. Scheffel J, Regen T, van RD et al. Toll-like receptor activation reveals developmental reorganization and unmasks responder subsets of microglia. Glia. 2012; 60:1930-1943

44. Weber MS, Prod'homme T, Patarroyo JC et al. B-cell activation influences T-cell polarization and outcome of anti-CD20 B-cell depletion in central nervous system autoimmunity. Ann Neurol. 2010; 68:369-383

45. Waetzig V, Czeloth K, Hidding U et al. c-Jun N-terminal kinases (JNKs) mediate proinflammatory actions of microglia. Glia. 2005; 50:235-246

46. Simmons SB, Pierson ER, Lee SY et al. Modeling the heterogeneity of multiple sclerosis in animals. Trends Immunol. 2013;

47. Xiao Y, Jin J, Chang M et al. Peli1 promotes microglia-mediated CNS inflammation by regulating Traf3 degradation. Nat Med. 2013; 19:595-602

48. Goldmann T, Wieghofer P, Muller PF et al. A new type of microglia gene targeting shows TAK1 to be pivotal in CNS autoimmune inflammation. Nat Neurosci. 2013; 16:1618-1626

49. Bettelli E, Carrier Y, Gao W et al. Reciprocal developmental pathways for the generation of pathogenic effector TH17 and regulatory T cells. Nature. 2006; $441: 235-238$ 
50. Das Sarma J, Ciric B, Marek R et al. Functional interleukin-17 receptor A is expressed in central nervous system glia and upregulated in experimental autoimmune encephalomyelitis. J Neuroinflammation. 2009; 6:14

51. Hanisch UK. Factors controlling microglial activation. In: Kettenmann H, Ransom B, eds. Neuroglia. New York: Oxford University Press, 2013:614-625

52. Hanamsagar R, Hanke ML, Kielian T. Toll-like receptor (TLR) and inflammasome actions in the central nervous system. Trends Immunol. 2012; 33:333-342

53. Gray P, Dunne A, Brikos C et al. MyD88 adapter-like (Mal) is phosphorylated by Bruton's tyrosine kinase during TLR2 and TLR4 signal transduction. J Biol Chem. 2006; 281:10489-10495

54. Gorina R, Sanfeliu C, Galito A et al. Exposure of glia to pro-oxidant agents revealed selective Stat1 activation by $\mathrm{H} 2 \mathrm{O} 2$ and Jak2-independent antioxidant features of the Jak2 inhibitor AG490. Glia. 2007; 55:1313-1324

55. Soltoff SP. Evidence that tyrphostins AG10 and AG18 are mitochondrial uncouplers that alter phosphorylation-dependent cell signaling. J Biol Chem. 2004; 279:10910-10918

56. Terada H. Uncouplers of oxidative phosphorylation. Environ Health Perspect. 1990; $87: 213-218$

57. Wüst S, Tischner D, John $\mathrm{M}$ et al. Therapeutic and adverse effects of a non-steroidal glucocorticoid receptor ligand in a mouse model of multiple sclerosis. PLoS One. 2009; 4:e8202

58. Akarasereenont $\mathrm{P}$, Thiemermann $\mathrm{C}$. The induction of cyclo-oxygenase- 2 in human pulmonary epithelial cell culture (A549) activated by IL-1beta is inhibited by tyrosine kinase inhibitors. Biochem Biophys Res Commun. 1996; 220:181-185 
59. Kelly SA, Goldschmidt-Clermont PJ, Milliken EE et al. Protein tyrosine phosphorylation mediates TNF-induced endothelial-neutrophil adhesion in vitro. Am J Physiol. 1998; 274:H513-H519

60. Mehta VB, Hart J, Wewers MD. ATP-stimulated release of interleukin (IL)-1beta and IL-18 requires priming by lipopolysaccharide and is independent of caspase-1 cleavage. J Biol Chem. 2001; 276:3820-3826

61. Li L, Cousart S, Hu J et al. Characterization of interleukin-1 receptor-associated kinase in normal and endotoxin-tolerant cells. J Biol Chem. 2000; 275:2334023345

62. Lin $\mathrm{CH}$, Kuan $\mathrm{IH}$, Wang $\mathrm{CH}$ et al. Lipoteichoic acid-induced cyclooxygenase-2 expression requires activations of p44/42 and p38 mitogen-activated protein kinase signal pathways. Eur J Pharmacol. 2002; 450:1-9

63. Kahlenberg JM, Dubyak GR. Differing caspase-1 activation states in monocyte versus macrophage models of IL-1beta processing and release. J Leukoc Biol. 2004; 76:676-684

64. Spitzer JA, Zhang P. Protein tyrosine kinase activity and the influence of gender in phagocytosis and tumor necrosis factor secretion in alveolar macrophages and lung-recruited neutrophils. Shock. 1996; 6:426-433

65. Bermejo DA, Jackson SW, Gorosito-Serran M et al. Trypanosoma cruzi trans-sialidase initiates a program independent of the transcription factors RORgammat and Ahr that leads to IL-17 production by activated B cells. Nat Immunol. 2013; $14: 514-522$

66. Boucheron N, Ellmeier W. The role of Tec family kinases in the regulation of Thelper-cell differentiation. Int Rev Immunol. 2012; 31:133-154 
67. Mukhopadhyay S, Sahoo PK, George A et al. Delayed clearance of filarial infection and enhanced Th1 immunity due to modulation of macrophage APC functions in xid mice. J Immunol. 1999; 163:875-883

68. Amedei A, Romagnani C, Benagiano M et al. Preferential Th1 profile of T helper cell responses in X-linked (Bruton's) agammaglobulinemia. Eur J Immunol. 2001; $31: 1927-1934$

69. Schmidt NW, Thieu VT, Mann BA et al. Bruton's tyrosine kinase is required for TLRinduced IL-10 production. J Immunol. 2006; 177:7203-7210

70. Horwood NJ, Page TH, McDaid JP et al. Bruton's tyrosine kinase is required for TLR2 and TLR4-induced TNF, but not IL-6, production. J Immunol. 2006; $176: 3635-3641$

71. Liu Y, Dong Y, Jiang QL et al. Bruton's tyrosine kinase: potential target in human multiple myeloma. Leuk Lymphoma. 2013;

72. Zorn CN, Keck S, Hendriks RW et al. Bruton's tyrosine kinase is dispensable for the Toll-like receptor-mediated activation of mast cells. Cell Signal. 2009; 21:7986

73. Hoffmann A, Kann O, Ohlemeyer C et al. Elevation of basal intracellular calcium as a central element in the activation of brain macrophages (microglia): suppression of receptor-evoked calcium signaling and control of release function. $\mathrm{J}$ Neurosci. 2003; 23:4410-4419

74. Doyle SL, Jefferies CA, O'Neill LA. Bruton's tyrosine kinase is involved in p65mediated transactivation and phosphorylation of p65 on serine 536 during NFkappaB activation by lipopolysaccharide. J Biol Chem. 2005; 280:2349623501 
75. Lee KG, Xu S, Kang ZH et al. Bruton's tyrosine kinase phosphorylates Toll-like receptor 3 to initiate antiviral response. Proc Natl Acad Sci U S A. 2012; 109:5791-5796

76. Liu X, Zhan Z, Li D et al. Intracellular MHC class II molecules promote TLRtriggered innate immune responses by maintaining activation of the kinase Btk. Nat Immunol. 2011; 12:416-424

77. Fitzner D, Schnaars M, van RD et al. Selective transfer of exosomes from oligodendrocytes to microglia by macropinocytosis. J Cell Sci. 2011; 124:447458

78. Hanisch UK. Functional diversity of microglia - how heterogeneous are they to begin with? Front Cell Neurosci. 2013; 7:65

79. Lehnardt S, Schott E, Trimbuch T et al. A vicious cycle involving release of heat shock protein 60 from injured cells and activation of toll-like receptor 4 mediates neurodegeneration in the CNS. J Neurosci. 2008; 28:2320-2331

80. Stewart CR, Stuart LM, Wilkinson K et al. CD36 ligands promote sterile inflammation through assembly of a Toll-like receptor 4 and 6 heterodimer. Nat Immunol. 2010; 11:155-161

81. Lehmann SM, Kruger C, Park B et al. An unconventional role for miRNA: let-7 activates Toll-like receptor 7 and causes neurodegeneration. Nat Neurosci. 2012;

82. Turpaev K, Drapier JC. Stimulatory effect of benzylidenemalononitrile tyrphostins on expression of NO-dependent genes in U-937 monocytic cells. Eur J Pharmacol. 2009; 606:1-8

83. Sagara $\mathrm{Y}$, Ishige $\mathrm{K}$, Tsai $\mathrm{C}$ et al. Tyrphostins protect neuronal cells from oxidative stress. J Biol Chem. 2002; 277:36204-36215 
84. Jaleel M, Shenoy AR, Visweswariah SS. Tyrphostins are inhibitors of guanylyl and adenylyl cyclases. Biochemistry. 2004; 43:8247-8255

85. Ramdas L, McMurray JS, Budde RJ. The degree of inhibition of protein tyrosine kinase activity by tyrphostin 23 and 25 is related to their instability. Cancer Res. 1994; 54:867-869

86. Mattsson E, Van DH, Van KK et al. Intracellular pathways involved in tumor necrosis factor-alpha release by human monocytes on stimulation with lipopolysaccharide or staphylococcal peptidoglycan are partly similar. J Infect Dis. 1996; 173:212-218

87. Muelas-Serrano S, Le-Senne A, Fernandez-Portillo C et al. In vitro and in vivo antiTrypanosoma cruzi activity of a novel nitro-derivative. Mem Inst Oswaldo Cruz. 2002; 97:553-557

88. Raghavan S, Subramaniyam G, Shanmugam N. Proinflammatory effects of malondialdehyde in lymphocytes. J Leukoc Biol. 2012; 92:1055-1067

89. Fischer MT, Sharma R, Lim JL et al. NADPH oxidase expression in active multiple sclerosis lesions in relation to oxidative tissue damage and mitochondrial injury. Brain. 2012; 135:886-899

90. Haider L, Fischer MT, Frischer JM et al. Oxidative damage in multiple sclerosis lesions. Brain. 2011; 134:1914-1924

91. Mauro C, Leow SC, Anso E et al. NF-kappaB controls energy homeostasis and metabolic adaptation by upregulating mitochondrial respiration. Nat Cell Biol. 2011; 13:1272-1279

92. Hong SH, Choi HB, Kim SU et al. Mitochondrial ligand inhibits store-operated calcium influx and COX-2 production in human microglia. J Neurosci Res. 2006; 83:1293-1298 
93. Chiang CY, Veckman V, Limmer K et al. Phospholipase Cgamma-2 and intracellular calcium are required for lipopolysaccharide-induced Toll-like receptor 4 (TLR4) endocytosis and interferon regulatory factor 3 (IRF3) activation. J Biol Chem. 2012; 287:3704-3709 


\section{FIGURES LEGENDS}

Figure 1: Effects of AG126 on disease outcomes in EAE. Mice immunized with MOG $35-55$ for EAE induction were treated as of day 12 for three consecutive days (arrows) with AG126 (500 $\mu$ g per animal, grey square) or vehicle (controls, open square). (A) Animals were scored daily for clinical signs of disease up to day 22. Data are mean \pm SEM, $n=5$ per group. Total scores as of day 12 differed significantly, ${ }^{* *} p<0.001$. (B) Histological analyses of spinal cord sections (day 23) revealed white matter lesions with massive demyelination (LFB-PAS staining), T cell infiltration (CD3 staining) and microglia activation (Iba1 staining) in controls (vehicle injection), whereas AG126-treated mice had less severe outcomes. Frames indicate positions of images on the right. Bars represent $100 \mu \mathrm{m}$ and $50 \mu \mathrm{m}$, respectively. (C) Lesion sizes in the experimental groups were quantified based on histology in (B), * $p=0.05$.

Figure 2: Effects of AG126 on T cell activation and CNS recruitment in EAE. EAE was induced as described in Fig 1. With the onset of clinical symptoms, animals were daily treated with AG126 or vehicle and sacrificed on day 5 for tissue preparation. (A) Splenocyte cultures were prepared, stimulated with $\mathrm{MOG}_{35-55}$ peptide for $72 \mathrm{~h}$ and analyzed for proliferation by $\left[{ }^{3} \mathrm{H}\right]$ thymidine incorporation. Data are mean $\pm \mathrm{SEM}, \mathrm{n}=5$ to 6 per group, measured in triplicates. Differences were statistically significant for all antigen concentrations $(* / * / * * / * *$, $p$ values of 0.013, 0.011, 0.006 and 0.006). (B) Supernatants of splenocyte cultures challenged with MOG $35-55$ for 72 h were analyzed for IL-2, IFN $\gamma$ and IL-17 concentrations to determine release from activated $\mathrm{T}$, Th1 and Th17 cells, respectively. Data are mean \pm SEM, $\mathrm{n}=6$ per group. For IL-2, only basal release values differed significantly between groups $\left({ }^{*} p=0.04\right)$. Differences in IL-17 production were significant throughout $(* / * *, 0.004 \leq p \leq 0.002)$. (C) FACS analyses of CNS tissues (brain and spinal cord) were performed to determine infiltrated T cells in general (CD3 ${ }^{+}$cells) as well as subpopulations of Th1 (IFN $\left.\gamma^{+}\right)$and Th17 (IL-17 $\left.{ }^{+}\right)$ 
type. The two panels show representative flow cytometry plots revealing reduced $\mathrm{T}$ cell infiltration in AG126-treated mice. (D) T cells of 2D2 mice, which are transgenic for a MOGspecific TCR, and T cell-free splenocytes from wt mice (used as APCs) were isolated, separately incubated with AG126 (100 $\mathrm{MM}, 1 \mathrm{~h})$ and combined for a stimulation with $\mathrm{MOG}_{35-}$ 55 peptide for $72 \mathrm{~h}$. The T cell-APC mixtures either received further AG126 to determine the general impact on the recall (left row) or continued in culture without AG126 to establish the impact of pre-treatment on either cell type (right row). Cytokine levels were then measured in the supernatants. Data are mean $\pm \mathrm{SEM}, 6 \leq \mathrm{n} \leq 24$ per group $(* / * * / * * *, p$ values $<0.05,<0.01$ and $<0.001)$.

Figure 3: Effects of AG126 on TLR-induced production of cytokines and chemokines. (A) Microglial cultures were stimulated with Pam $_{3} \mathrm{CSK}_{4}$, LPS, MALP (all $10 \mathrm{ng} / \mathrm{ml}$ ), poly(I:C) $(50 \mu \mathrm{g} / \mathrm{ml})$ or CpG ODN (5 $\mu \mathrm{g} / \mathrm{ml})$ in the presence of varying concentrations of AG126 for 18 h (including pre-incubation with AG126 for 1 h). Indicated cytokines and chemokines were determined in the supernatants and amounts were expressed as percentage of the release obtained from stimulations in AG126 absence. (B) Microglia were treated with TLR agonists and AG126 as in (A) and IFN $\beta$ release was measured. (C) As in (B), IFN $\beta$ production was determined for LPS-stimulated microglia from myd88 $8^{-/}$, trif $^{\text {ps2 }}$ and matching wt mice in the absence or presence of AG126 (100 $\mu \mathrm{M})$. Amounts obtained under AG126 were expressed as percentage of the release in wt controls, levels being generally lower in myd88 ${ }^{--}$than in wt cells. Data are mean \pm SEM, with (A) $n=24$ per treatment (summarized from two experiments), (B) $n=6$ and (C) n=4. All studies were accompanied by assays on cell viability, based on WST-1 conversion. AG126 itself did not cause any release and did not impair cell vitality under any condition. 
Figure 4: AG126 effects on TLR-controlled MHC expression and myelin phagocytosis. (A) Microglia were stimulated with $\mathrm{Pam}_{3} \mathrm{CSK}_{4}$, LPS, MALP (10 ng/ml) or poly(I:C) (50 $\mu \mathrm{g} / \mathrm{ml}$ ) for $48 \mathrm{~h}$ in the absence or presence of AG126 (10 or $100 \mu \mathrm{M}$, including $1 \mathrm{~h}$ preincubation), Fc $\gamma$ RII/III-blocked, stained with FITC-ILB 4 and APC-anti-MHCI antibody and processed for flow cytometry. Representative histograms ( $10^{5}$ cells per sample) out of two experiments are shown. Parallel analyses for MHCII revealed no induction, whereas treatment with IFN $\gamma(10 \mathrm{ng} / \mathrm{ml}$ as a control) resulted in a clear upregulation, which could not be blocked by AG126. (B, C) Microglia were treated with TLR agonists and AG126 as in (A) for 24 h, exposed to FITC-myelin for 30 or 120 min, labeled with APC-anti-CD11b antibody and processed for flow cytometry. Representative color-coded contour blots in (B) were based on $1.5 \times 10^{4}$ cells each. Mean fluorescence intensity (MFI) was normalized for unstimulated cells with 120 min FITC-myelin exposure in (C). Data are mean \pm SEM from 2 independent experiments. Significant differences are indicated for comparisons between controls and TLRstimulated cells $\left({ }^{\#}\right)$ as well as cells with and without AG126 treatment $\left(^{*}\right) .{ }^{* *} p<0.05$, ${ }^{* *} p<0.01 ;$ n.s., not significant.

Figure 5: AG126 and LFM-A13 effects on BTK activity and TLR-induced cytokines. (A) A library of immobilized peptides containing tyrosine in random sequences was phosphorylated by recombinant BTK (50 ng/ml) using ATP in the absence or presence of AG126 or LFM-A13 at indicated concentrations. Phospho-Tyr was detected with a HRPconjugated antibody. Data are mean $\pm \mathrm{SEM}, \mathrm{n}=4$ per group from two experiments. For a direct comparison, the graph also contains data on BZ and MN (see Fig 6). (B) Ramos cells were stimulated with anti-human IgM for $1 \mathrm{~min}$ in the absence or presence of AG126 or LFM-A13 (including $1 \mathrm{~h}$ preincubation). Cleared cell lysates were processed for SDS-PAGE and immunoblot analysis with anti-phospho-PLCy2(Y759) antibody. Membranes were stripped and re-probed with an antibody against PLC $\gamma 2$. Blots are taken from one of two 
experiments. (C) Microglia were stimulated with TLR agonists as described in Fig 1. TNF $\alpha$ and CXCL1 release was determined in the absence or presence of AG126 or LFM-A13 at indicated concentrations (including $1 \mathrm{~h}$ pre-incubation). Data are mean $\pm \mathrm{SEM}, \mathrm{n}=12$ from two experiments.

Figure 6: Correlation of effects between AG126 and its degradation products. (A) Equation of the AG126 conversion to 3-hydroxy-4-nitro-benzaldehyde (BZ) and malononitrile (MN). (B) Microglia were stimulated with Pam $_{3} \mathrm{CSK}_{4}$, LPS or MALP (10 $\mathrm{ng} / \mathrm{ml}$ ) for $18 \mathrm{~h}$ in the absence or presence of AG126, BZ or MN (including $1 \mathrm{~h}$ preincubation). CCL2 levels were measured in the supernatants and expressed as percentage of the release obtained with the respective TLR agonists alone. Data are mean \pm SEM, $n=6$ from 2 experiments. (C) A correlation between the effects of AG126 and MN on release activities was based on 90 data pairs obtained from TLR1/2, TLR4 and TLR6/2 inductions of TNF $\alpha$, IL-6, CXCL1, CCL2, CCL3 and CCL5 in the presence of various concentrations of the compounds (as in B).

Figure 7: Effects of AG126, MN and BZ on disease outcomes in EAE. (A) EAE was induced as described in Figs 1 and 2. Upon disease onset, animals received AG126 or respective amounts of $\mathrm{MN}$ and $\mathrm{BZ}$, or only vehicle (arrows indicate three daily injections, followed by two administrations every other day, see also Supplementary Fig 2). Clinical symptoms were scored up to day 30 when the animals got sacrificed for tissue analyses. Data are mean \pm SEM, based on 11, 12, 11 and 10 animals with control, MN, BZ and AG126 treatment, respectively. (B) Representative spinal cord sections from these animals reveal lesions in LFB-PAS staining (asterisks marking pink areas within blue white matter staining). The bar graph shows the quantification of the lesion sizes (mean \pm SEM, $10 \leq n \leq 12$ per group as in A). (C) Quantification of $\mathrm{CD}^{+}$cell infiltrates was performed in spinal cord sections of 
the animals in (A), based on a ranking ( 0 for $<20,+$ for 21 to $50,++$ for 51 to 100 and +++ for $>100$ cells/area). (D) Quantification of Iba1 ${ }^{+}$cells was performed in spinal cord sections of the animals in (A), based on a similar ranking as in (C). (E) Spleen weight was also determined in these animals. Data are mean \pm SEM. (F) Blood samples were taken on day 14 (\# in A) and cytokine levels were determined in the serum. (G) Individual levels of the cytokines in (F) were plotted against the disease score across groups.

Figure 8: Scheme of assumed mechanisms of AG126/MN actions. TLR4-agonistic PAMPs ('S-mooth' and 'R-ough' LPS chemotypes) or DAMPs (covering a range of intracellular, plasma and ECM proteins as well as carbohydrate structures) can trigger in cells, such as microglia, the induction of proinflammatory cytokines/chemokines for recruitment of immune cells. In conjunction with co-receptors, such as CD14, a TLR4/MD2 complex signals through pathways involving sorting (TRAM, TIRAP/MAL) and signaling adaptor proteins (TRIF, MyD88). MyD88 activation occurs at the cell surface-expressed TLR4, TRIF engagement requires CD14-assisted TLR4 endocytosis and signaling from endosomal compartments. Both routes cause an activation of kinase cascades (including MAPK) and transcription factors (e.g. IRF, AP-1 or NFאB). MyD88 organizes expression of a variety of factors, such as TNF $\alpha$ or CXCL1. TRIF characteristically drives IFN $\beta$ production. AG126 can inhibit BTK, a PTK best known for its role in BCR calcium signaling. In addition, BTK can interact with TLR4 and phosphorylate TIRAP/MAL. Modulation of microglial functions likely involves a direct impact of AG126 on BTK and calcium elevation, but also contributions of MN, an AG126 breakdown product. AG126/MN effects are noticed for MyD88-dependent responses, whereas TRIF-inducible functions are largely spared. Note that other signaling elements were omitted for clarity. 


\section{SUPPLEMENTARY MATERIALS}

\section{Supplementary Figure 1: Histological analyses of spinal cord sections in animals with}

EAE reveal protective effects of AG126. Tissue sections as shown in Fig 1 were also processed for HE and Bielschowsky staining to determine total immune infiltrates and axonal injury. Images relate to the frames shown in Fig 1B (left, for AG126 treatment, right, for controls). Bars represent $50 \mu \mathrm{m}$.

Supplementary Figure 2: AG126 partially improves the disease course in EAE also by a late therapeutic rather than by preventive treatment. (A) Mice MOG 35 -55-immunized for EAE induction received AG126 (500 $\mu \mathrm{g}$ per animal) or vehicle on three consecutive days followed by two administrations every other day (arrows). The delivery started either as of day 7 as a preventive treatment (pv, before the onset of the clinical symptoms) or as of day 15 as a late therapeutic treatment (tp, after the onset of symptoms). Blood samples were taken in the middle of either of the 5-days treatment trains (\#). Data are mean \pm SEM, $n=7$ per group. (B) Animals from (A) were sacrificed on day 30 for histological analyses of spinal cord sections. Representative hemisections with LFB-PAS staining of white matter are shown for animals that had received either preventive or therapeutic AG126 treatments, next to tissues of their respective controls (vehicle delivery only). Asterisks mark lesion sites with pink areas within blue white matter staining. The bar represents $100 \mu \mathrm{m}$. Data from a quantification of the lesion sizes are shown below. (C) Blood samples taken on days 10 or 18 (preventive and therapeutic treatments, respectively) were analyzed for leukocyte populations. The CD11b cells would comprise monocytes, macrophages, granulocytes and natural killer cells while flow cytometry with antibodies against CD3 and Ly6G in combination with anti-CD11b identifies T cells or monocytes/granulocytes. 


\section{Supplementary Figure 3: TLR agonists induce microglial cytokine and chemokine}

production. (A) Primary cultures of wt microglia were treated with the specific TLR agonists $\mathrm{Pam}_{3} \mathrm{CSK}_{4}$ (TLR1/2), LPS E.coli R515 (TLR4), flagellin (TLR5), MALP2 (TLR6/2), poly(U) (TLR7/8) and CPG ODN (TLR9) in pathophysiological relevant concentration ranges. Poly(I:C) was employed for TLR3 activation (as it was found more suitable than poly(A:U)), but also acts on other PRRs. After $18 \mathrm{~h}$ of exposure, cyto- and chemokine concentrations were determined in the supernatants. The spectrum of factors comprised TNF $\alpha$ as a pluripotent cytokine with general pro-inflammatory actions, IL-6 as a pro- as well as anti-inflammatory cytokine with multiple cellular targets and induction also upon injuries and associated recruitment of T and B cells, IL-10 as a potent suppressor of macrophage functions, IL-12 as a cytokine associated with CD4 T cell differentiation into the Th1 subtype and production by M1-polarized macrophages (either determined as p40 total to cover all molecular versions containing the p40 subunit in monomeric hetero- and homodimeric form or measured as p70 to focus on the heteromeric p35/p40 version), CCL2 (MCP1), a chemokine attracting T cells, monocytes, basophils and activating macrophages, CCL3 (MIP1 $\alpha$ ) as a chemokine attracting monocytes/macrophages, T cells (Th1>Th2), NK cells, basophils and immature dendritic cells, CCL5 (RANTES) as an attractor of monocytes/macrophages, T cells ( $\mathrm{T}$ memory cells>Tcells, Th1>Th2), being also involved in chronic inflammation, CCL22 (MDC) causing chemotactic migration of dendritic cells and Th2 cells as well as CXCL1 (KC), as a potent attractor of neutrophils. IFN $\beta$ was included as a factor for antiviral defense and because of its exclusive TRIF dependence, allowing conclusions about AG126 effects on this route (see also Fig 3). Arrows indicate the standard concentrations applied in subsequent experiments. (B) Consistent with the release responses, RT-PCR analyses revealed expression of TLR1, 2, 3, 4, 6, 8 and 9 and absence of TLR5. A product was also detected for TLR7 upon varied amplification conditions. Data are mean \pm SEM, with $n>20$ culture wells from 2 experiments. 


\section{Supplementary Figure 4: AG126 affects MyD88-dependent cytokine and chemokine}

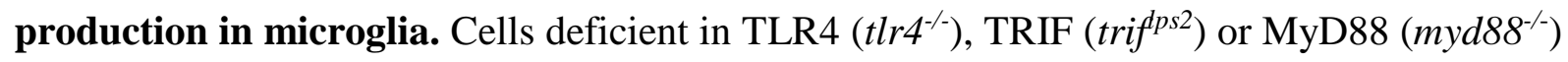
were compared to matching wt cells as to the production of TNF $\alpha$ and CXCL1 upon stimulation with agonists of TLR1/2 (Pam $\left.3 \mathrm{CSK}_{4}, 10 \mathrm{ng} / \mathrm{ml}\right)$, TLR4 (LPS, $\left.10 \mathrm{ng} / \mathrm{ml}\right)$ and TLR6/2 (MALP, $10 \mathrm{ng} / \mathrm{ml})$ in the absence (control, CTL) and presence of AG126 (100 $\mu \mathrm{M})$ for $18 \mathrm{~h}$. Treatment with AG126 included a pre-incubation for $1 \mathrm{~h}$. Release was determined as in Fig S3. Data are mean \pm SEM, with $16 \leq \mathrm{n} \leq 24$ per treatments of wt, $t l r 4^{-/}$, trif $f^{p s 2}$ and myd88/- cells, respectively, as summarized from 2 to 4 preparations.

\section{Supplementary Figure 5: AG126 has little effects on TLR downstream signaling at the} levels of NFKB and MAPK. (A) Microglia were stimulated with LPS (10 ng/ml) in the absence or presence of AG126 (50 $\mu \mathrm{M})$ for 30 min. Treatment with AG126 included a $1 \mathrm{~h}$ pre-incubation. Nuclear translocation of NFאBp65 was detected as by immunocytochemistry, the signal (red, rabbit-anti-phospho-NFкB antibody) appearing in the nucleus (blue, DAPI) of the cells (green, FITC-labeled isolectin $\mathrm{B}_{4}, \mathrm{ILB}_{4}$, for surface carbohydrate staining). (B) Microglia were stimulated and treated with AG126 as in (A) for the indicated periods. Phosphorylated and total JNK proteins (variants of 46 and $54 \mathrm{kD}$ ) were detected by immunoblotting in cleared microglial lysates, after adjusting total protein contents. Representative blots of 2 experiments are shown. (C) Microglia were treated as in (A) for the indicated periods. Phosphorylation of NFkBp65 (Ser536), p38 ${ }^{\mathrm{MAPK}}$ (Thr180/Tyr182) and ERK1/2 (Thr202/Tyr204) was quantified by ELISA in lysate samples of equal protein concentration, as also revealed by GAPDH Western blots. Data are mean \pm SEM, $n=3$ from 2 experiments. (D) Microglia were stimulated with $\mathrm{Pam}_{3} \mathrm{CSK}_{4}(10 \mathrm{ng} / \mathrm{ml})$ for $15 \mathrm{~min}$ with and without AG126 $(100 \mu \mathrm{M})$, including a preincubation as in (A). Cell lysates were then subjected to a phospho-MAPK array. Spot intensities were determined and normalized to the respective controls. This human protein array has been confirmed as applicable to certain 
mouse factors, including ERK2. Data are mean \pm SEM, $n=2$. Panels (A) to (C) present examples of experiments involving stimulations of TLR1/2, TLR3, TLR4 and TLR6/2 and giving similar outcomes.

Supplementary Figure 6: BTK is expressed in microglia but not in T cells. (A) Microglial

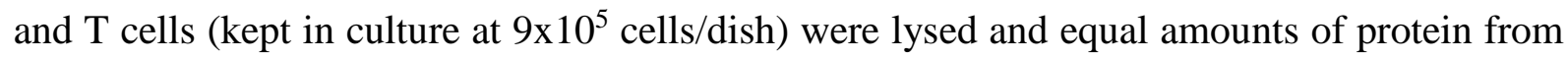
the cleared lysates were separated by SDS-PAGE (non-reducing conditions), transferred to PVDF membrane and processed for detection with an anti-BTK antibody and a secondary antibody-HRP conjugate. Constitutive BTK expression was determined in untreated microglia (kept in medium, CTL). Effects of TLR4 activation were considered by stimulation of cells with LPS (10 ng/ml) for $18 \mathrm{~h}$ prior to lysis. Molecular weight markers indicated the expected size. The blot is representative for 3 preparations and treatments each, respectively. (B) Microglia were treated with LPS or just kept in medium (as in A) and stained with anti-BTK as well as Cy3-labelled secondary antibodies, FITC-ILB 4 and DAPI. Images reveal the nuclear (blue), cell surface (green) and BTK (red) stainings as well as the respective overlays. The insert represents non-specific labeling by the secondary antibody (red) as determined by omitting the anti-BTK antibody from the protocol. For clarity, these cells were only counterstained with DAPI, but not with FITC-ILB4. BTK expression in microglia was further confirmed at the mRNA level by an Illumina HiSeq2000 approach. Reporter sequences were identified under constitutive and various activating conditions.

\section{Supplementary Figure 7: AG126 does not affect the membrane potential of microglial}

mitochondria. Microglia were preincubated with AG126 (100 $\mu \mathrm{M})$ or just received medium for $1 \mathrm{~h}$, followed by treatment with TLR agonists $(10 \mathrm{ng} / \mathrm{ml})$ in the absence or presence of AG126 $(100 \mu \mathrm{M})$ for $18 \mathrm{~h}$. Subsequently, cells were stained with JC-1. Fluorescence intensities of monomers (green) and aggregates (red) were measured and expressed as their 
ratio to evaluate mitochondrial integrity. As positive controls, cells were treated with valinomycin for 20 min to enforce a collapse in the membrane potential. Data are mean \pm SEM, with $\mathrm{n}>12$ per group as taken from 2 experiments.

Supplementary Figure 8: AG126 does not act through adrenergic receptors. Microglia were stimulated via TLR1/2 (Pam $\left.3 \mathrm{CSK}_{4}, 10 \mathrm{ng} / \mathrm{ml}\right)$ for $18 \mathrm{~h}$ in the absence or presence of AG126 $(100 \mu \mathrm{M})$ alone or in combination with phentolamine methanesulfonate (PAMS, 1, 10 and $100 \mu \mathrm{M}$ ) or propranolol (PR, 0.1, 1 and $10 \mu \mathrm{M}$ ). TNF $\alpha$ and CXCL1 release was determined in the supernatants and expressed as percentage of the amounts obtained with TLR agonist alone (bars). Cell viability was determined by WST-1 assay (circles). Substrate conversion was expressed as percentage of the value obtained with unstimulated cells. Data are mean \pm SEM, with $n=16$ per group from 2 experiments.

Supplementary Figure 9: AG126 does not act via glucocorticoid receptors. Microglia were prepared from $\mathrm{gr}^{+/-}, \mathrm{gr}^{-/-}$and $\mathrm{gr}^{+/+}$(wt) mice at embryonic day E18.5, since complete GR loss is lethal at later stages. Cells were stimulated with $\mathrm{Pam}_{3} \mathrm{CSK}_{4}(10 \mathrm{ng} / \mathrm{ml})$ in the absence or presence of dexamethasone (DEX, $0.1 \mu \mathrm{M}$ ) or AG126 (100 $\mu \mathrm{M})$ for $18 \mathrm{~h}$, involving also respective preincubations for $1 \mathrm{~h}$. TNF $\alpha$ and CXCL1 amounts were determined in the supernatants and expressed as percentage of the release obtained with TLR stimulation alone. Cell viability was assessed by a WST-1 assay (see Fig S8). Data are mean \pm SEM, with $n=16$ from 2 experiments.

Supplementary Figure 10: COX2 activity does not play a major role in TLR-triggered cytokine and chemokine release by microglia. Microglia were stimulated with (A) $\mathrm{Pam}_{3} \mathrm{CSK}_{4}$, (B) LPS or (C) MALP (all at $10 \mathrm{ng} / \mathrm{ml}$ ) in the absence or presence of COX1 or COX2 inhibitors (FR122047, SC-791, 1-[4,5-bis(4-methoxyphenyl-2-thiazoyl)carbonyl]-4- 
methylpiperazine, 4-[(5-difluoromethyl-3-phenyl)-4-isoxazolyl]benzenesulfonamide) or their combination at various concentrations for $18 \mathrm{~h}$. Cytokines and chemokines were determined in the culture supernatants and amounts were expressed as percentage of the release obtained from stimulations without an inhibitor. Data are mean \pm SEM with $n=12$ to 33 from 2 to 3 experiments.

\section{Supplementary Figure 11: NMR analyses reveal fragmentation of AG126 in aqueous}

environment. (A) AG126 dissolved in DMSO with residual amounts of water $(10 \mathrm{mg} / \mathrm{ml}$, $\mathrm{DMSO}_{\mathrm{aq}}$ ) was analyzed by ${ }^{1} \mathrm{H}$ NMR spectroscopy. Spectra were taken directly or after 2 and 8 $\mathrm{h}$ as well as 5 and 26 days of incubation. Characteristic AG126 peaks are indicated by colored triangles and explained in (C). The gray triangle indicates a newly appearing peak being characteristic for an aldehyde. (B) AG126 was dissolved in $\mathrm{DMSO}_{\mathrm{aq}}$ or in $\mathrm{DMSO}_{\text {aq }}$ mixed with $\mathrm{D}_{2} \mathrm{O}$ (1 volume plus 3 volumes). ${ }^{1} \mathrm{H}$ NMR spectra were taken at the different time periods as indicated. The integral of the AG126 peak (white square, $\mathrm{DMSO}_{\mathrm{aq}}, 8.57 \mathrm{ppm}$, DMSO $+\mathrm{D}_{2} \mathrm{O}, 8.25 \mathrm{ppm}$, the peak shift being caused by the solvent) and an aldehyde peak (black circle, $10.0 \mathrm{ppm}$ ) were plotted against time of AG126 incubation. (C) ${ }^{1} \mathrm{H}$ atoms with the corresponding ppm value are highlighted on the chemical structure of AG126. ${ }^{13} \mathrm{C}$ atoms are correlated to a 2D HMBC (two and three-bond or heteronuclear multiple bond correlation) spectrum of AG126 dissolved in DMSO, with the ${ }^{1} \mathrm{H}$ NMR spectrum shown on top and the

${ }^{13} \mathrm{C}$ NMR spectrum shown on the left. Traces along the characteristic $\mathrm{H}$ atoms (again marked with colored triangles) are drawn as dashed lines. Observed ${ }^{13} \mathrm{C}$ resonances are connected to the corresponding C atoms in the AG126 structure by black arrows, based on correlation of nearby $\mathrm{H}$ atoms with heteronuclear single quantum coherence, one-bond correlation, and HMBC spectra. (D) Overlay of the 2D HMBC spectra of AG126 dissolved in DMSO (green) and in DMSO $+\mathrm{D}_{2} \mathrm{O}$ (red). The peaks in the two samples are slightly shifted due to different solvent compositions. Addition of $\mathrm{D}_{2} \mathrm{O}$ led to the appearance of new signals corresponding to 
an aldehyde. The carbonyl ${ }^{13} \mathrm{C}$ resonance is at $192.7 \mathrm{ppm}$, but appears folded at $82.7 \mathrm{ppm}$. The gray dotted line illustrates the cutout shown in (C). The box in the ${ }^{1} \mathrm{H}$ spectrum indicates $\mathrm{H}_{2}$ protons as analyzed by diffusion-ordered spectroscopy, which was performed to detect further (breakdown) structures according to their substance size. (E) Overlay of 2D HMBC spectra of AG126 dissolved in DMSO $+\mathrm{D}_{2} \mathrm{O}$ and $\mathrm{BZ}$ as an identified breakdown product. While the pure sample of BZ revealed the aldehyde signals, the $\mathrm{C}$ atoms of the nitrile part of AG126 were not detected, as expected. The stoichiometric balance suggested malononitrile (MN) as a second product. However, MN could not be identified directly in ${ }^{1} \mathrm{H}$ NMR spectra, presumably because the $\mathrm{CH}_{2}$ resonance was hidden under the residual water signal or because of a transformation into a $\mathrm{CD}_{2}$ group by exchange with the solvent.

\section{Supplementary Figure 12: Correlation of effects between AG126 and related tyrphostin} members. The chemical structure illustrates individual substitutions at the ring positions as they differ from AG126. Microglia were stimulated with the TLR agonists in the absence or presence of tyrphostins as in Fig 6. TNF $\alpha$ and CXCL1 amounts were determined and expressed as percent of control levels. Data are mean \pm SEM, with $n=8$ from 2 experiments. AG17 was excluded from the release data presentation since it probably impaired the cell vitality, as indicated by reduced WST-1 conversion.

\section{Supplementary Table 1: Microglial cytokine and chemokine release in response to} stimulation with IL-17 and TLR agonists. Microglial cultures were stimulated with IL-17A or IL-17E either alone or in combination with $\mathrm{Pam}_{3} \mathrm{CSK}_{4}$ or LPS for $18 \mathrm{~h}$ at the indicated concentrations. Cytokines and chemokines were determined in the supernatants. Data are mean \pm SEM with $n=8$ to 16 per group as taken from 2 experiments. Statistical analyses were performed by the Mann-Whitney $U$ test. ${ }^{*} p<0.05$, ${ }^{* *} p<0.01$ and ${ }^{* * *} p<0.001$ as to significant differences compared to medium control; ${ }^{*} p(\bullet)<0.05$ for significant difference between the 
combined stimulation with a TLR agonist ( $\mathrm{Pam}_{3} \mathrm{CSK}_{4}$ or LPS) and an IL-17 form compared to the respective TLR stimulation alone; n.d., not detectable. 17A or IL-17E alone induced some significant but only minute amounts of TNFa, CCL2, CCL3, CCL5 and CXCL1. While all combined stimulations were significantly different from the medium control (with $p<0.001$, not further indicated), the IL-17 proteins had only small effects in addition. 


\section{SUPPLEMENTARY TABLE}

Supplementary Table 1: Microglial cytokine and chemokine release in response to stimulation with IL-17 and TLR agonists. Microglial cultures were stimulated with IL-17A or IL-17E either alone or in combination with $\mathrm{Pam}_{3} \mathrm{CSK}_{4}$ or LPS for $18 \mathrm{~h}$ at the indicated concentrations. Cytokines and chemokines were determined in the supernatants. Data are mean \pm SEM with $n=8$ to 16 per group as taken from 2 experiments. Statistical analyses were performed by the Mann-Whitney $U$ test. ${ }^{*} p<0.05,{ }^{* *} p<0.01$ and ${ }^{* * *} p<0.001$ as to significant differences compared to medium control; ${ }^{*} p(\bullet)<0.05$ for significant difference between the combined stimulation with a TLR agonist (Pam ${ }_{3} \mathrm{CSK}_{4}$ or LPS) and an IL-17 form compared to the respective TLR stimulation alone; n.d., not detectable. 17A or IL-17E alone induced some significant but only minute amounts of TNF $\alpha$, CCL2, CCL3, CCL5 and CXCL1. While all combined stimulations were significantly different from the medium control (with $p<0.001$, not further indicated), the IL-17 proteins had only small effects in addition.

\begin{tabular}{|c|c|c|c|c|c|c|c|}
\hline \multicolumn{2}{|c|}{ Treatment } & \multicolumn{6}{|c|}{ Concentration [pg/ml] } \\
\hline Factor & [g/ml] & TNF $\alpha$ & IL-6 & CCL2 & CCL3 & CCL5 & CXCL1 \\
\hline medium & & $2.3 \pm 0.9$ & $3.7 \pm 1.5$ & $7.0 \pm 1.7$ & $63.3 \pm 15.7$ & n.d. & n.d. \\
\hline \multirow[t]{3}{*}{ IL-17A } & $10^{-9}$ & $\begin{array}{c}7.0 \pm 1.9 \\
* p=0.032\end{array}$ & $5.6 \pm 2.6$ & $9.8 \pm 2.8$ & $92.6 \pm 13.7$ & n.d. & n.d. \\
\hline & $10^{-8}$ & $\begin{array}{l}13.1 \pm 3.7 \\
* \mathrm{p}=0.015\end{array}$ & $5.7 \pm 4.4$ & $13.6 \pm 4.3$ & $\begin{array}{l}132.2 \pm 13.5 \\
* * \mathrm{p}=0.008\end{array}$ & $\begin{array}{c}75.2 \pm 23.6 \\
* * * \mathrm{p}<0.001\end{array}$ & n.d. \\
\hline & $10^{-7}$ & $\begin{array}{l}15.3 \pm 5.1 \\
*_{p}=0.030\end{array}$ & $11.2 \pm 4.8$ & $\begin{array}{c}29.5 \pm 4.0 \\
* * * \mathrm{p}<0.001\end{array}$ & $\begin{array}{l}149.9 \pm 11.9 \\
* * \mathrm{p}=0.002\end{array}$ & $\begin{array}{c}28.8 \pm 14.1 \\
* \mathrm{p}=0.011\end{array}$ & $\begin{array}{c}11.7 \pm 6.0 \\
* * \mathrm{p}=0.003\end{array}$ \\
\hline \multirow[t]{3}{*}{ IL-17E } & $10^{-9}$ & $\begin{array}{l}10.6 \pm 2.8 \\
* \mathrm{p}=0.011\end{array}$ & $8.4 \pm 3.0$ & $15.6 \pm 3.5$ & $\begin{array}{c}114.3 \pm 12.2 \\
*_{p}=0.019\end{array}$ & $5.4 \pm 5.1$ & n.d. \\
\hline & $10^{-8}$ & $\begin{array}{c}15.8 \pm 3.8 \\
* * \mathrm{p}=0.001\end{array}$ & $5.7 \pm 2.6$ & $14.8 \pm 3.1$ & $\begin{array}{l}134.3 \pm 9.6 \\
* * \mathrm{p}=0.002\end{array}$ & $\begin{array}{l}103.3 \pm 29.8 \\
* * * \mathrm{p}<0.001\end{array}$ & n.d. \\
\hline & $10^{-7}$ & $\begin{array}{c}25.5 \pm 4.9 \\
* * * \mathrm{p}<0.001\end{array}$ & $8.4 \pm 3.1$ & $\begin{array}{c}24.6 \pm 4.3 \\
* * p=0.005\end{array}$ & $\begin{array}{l}142.2 \pm 11.6 \\
* * \mathrm{p}=0.003\end{array}$ & $\begin{array}{c}15.7 \pm 9.5 \\
* * \mathrm{p}=0.003\end{array}$ & $\begin{array}{c}8.2 \pm 3.4 \\
* * \mathrm{p}=0.003\end{array}$ \\
\hline $\mathrm{Pam}_{3} \mathrm{CSK}_{4}$ & $10^{-8}$ & $\begin{array}{l}2648.8 \pm 68.7 \\
* * * \mathrm{p}<0.001\end{array}$ & $\begin{array}{l}2663.9 \pm 46.8 \\
* * * \mathrm{p}<0.001\end{array}$ & $\begin{array}{l}653.7 \pm 67.2 \\
* * * p<0.001\end{array}$ & $\begin{array}{c}13621.8 \pm 1201.0 \\
* * * \mathrm{p}<0.001\end{array}$ & $\begin{array}{c}4191.3 \pm 255.5 \\
* * * \mathrm{p}<0.001\end{array}$ & $\begin{array}{c}5228.2 \pm 401.7 \\
* * * \mathrm{p}<0.001\end{array}$ \\
\hline \multirow[t]{3}{*}{ + IL-17A } & $10^{-9}$ & $2530.7 \pm 142.0$ & $2418.5 \pm 165.8$ & $693.3 \pm 88.8$ & $16421.6 \pm 2020.6$ & $3986.9 \pm 280.3$ & $4751.4 \pm 441.8$ \\
\hline & $10^{-8}$ & $2858.5 \pm 150.3$ & $\begin{array}{c}3010.6 \pm 185.0 \\
*_{p}=0.035(\bullet)\end{array}$ & $762.1 \pm 91.9$ & $14105.7 \pm 2025.9$ & $4611.9 \pm 274.5$ & $5816.1 \pm 780.3$ \\
\hline & $10^{-7}$ & $2579.1 \pm 74.5$ & $2579.3 \pm 104.2$ & $812.8 \pm 116.6$ & $14970.5 \pm 1177.7$ & $4173.8 \pm 282.4$ & $4927.5 \pm 527.4$ \\
\hline + IL-17E & $10^{-9}$ & $2547.5 \pm 83.9$ & $2445.9 \pm 148.8$ & $634.7 \pm 105.9$ & $13134.8 \pm 813.7$ & $4010.5 \pm 418.0$ & $4792.5 \pm 631.9$ \\
\hline
\end{tabular}




\begin{tabular}{|c|c|c|c|c|c|c|c|}
\hline & $10^{-8}$ & $\begin{array}{l}2401.8 \pm 92.6 \\
*_{p}=0.032(\bullet)\end{array}$ & $\begin{array}{c}2397.8 \pm 116.3 \\
* p=0.047(\bullet)\end{array}$ & $577.3 \pm 68.8$ & $21271.7 \pm 9115.6$ & $3965.5 \pm 232.5$ & $4690.1 \pm 382.6$ \\
\hline & $10^{-7}$ & $2312.4 \pm 205.4$ & $\begin{array}{l}2452.0 \pm 84.7 \\
* p=0.037(\bullet)\end{array}$ & $609.6 \pm 69.6$ & $11553.8 \pm 1076.2$ & $3951.8 \pm 255.2$ & $4691.7 \pm 520.3$ \\
\hline LPS & $10^{-8}$ & $\begin{array}{c}3230.2 \pm 217.5 \\
* * * \mathrm{p}<0.001\end{array}$ & $\begin{array}{c}6445.0 \pm 759.2 \\
* * * \mathrm{p}<0.001\end{array}$ & $\begin{array}{c}2476.2 \pm 333.9 \\
* * * \mathrm{p}<0.001\end{array}$ & $\begin{array}{c}13298.4 \pm 1295.1 \\
* * * \mathrm{p}<0.001\end{array}$ & $\begin{array}{c}28803.9 \pm 335.1 \\
* * * \mathrm{p}<0.001\end{array}$ & $\begin{array}{l}1500.1 \pm 95.6 \\
* * * \mathrm{p}<0.001\end{array}$ \\
\hline \multirow[t]{3}{*}{ + IL-17A } & $10^{-9}$ & $3754.2 \pm 225.8$ & $6764.7 \pm 907.6$ & $\begin{array}{c}3359.1 \pm 480.0 \\
* * \mathrm{p}=0.002\end{array}$ & $15732.0 \pm 2500.4$ & $28978.0 \pm 473.4$ & $1688.0 \pm 151.8$ \\
\hline & $10^{-8}$ & $3243.3 \pm 187.9$ & $6472.7 \pm 1016.1$ & $\begin{array}{c}3743.9 \pm 310.6 \\
{ }^{*} \mathrm{p}=0.027(\bullet)\end{array}$ & $15445.3 \pm 2073.9$ & $28432.1 \pm 448.6$ & $1465.4 \pm 160.6$ \\
\hline & $10^{-7}$ & $3557.2 \pm 238.3$ & $6519.8 \pm 918.6$ & $3371.7 \pm 301.6$ & $14307.5 \pm 2594.4$ & $29932.1 \pm 541.4$ & $1803.0 \pm 109.3$ \\
\hline \multirow[t]{3}{*}{ + IL-17E } & $10^{-9}$ & $3217.3 \pm 161.6$ & $5829.5 \pm 980.5$ & $3041.7 \pm 462.1$ & $12211.5 \pm 1554.5$ & $28459.4 \pm 373.4$ & $1327.2 \pm 120.4$ \\
\hline & $10^{-8}$ & $3929.5 \pm 592.9$ & $6676.6 \pm 925.1$ & $2872.6 \pm 306.9$ & $12606.0 \pm 1351.7$ & $28238.6 \pm 401.4$ & $1720.3 \pm 54.1$ \\
\hline & $10^{-7}$ & $3160.7 \pm 126.6$ & $5274.8 \pm 667.8$ & $3197.2 \pm 393.9$ & $16905.3 \pm 5107.9$ & $27972.8 \pm 477.9$ & $1629.7 \pm 80.5$ \\
\hline
\end{tabular}




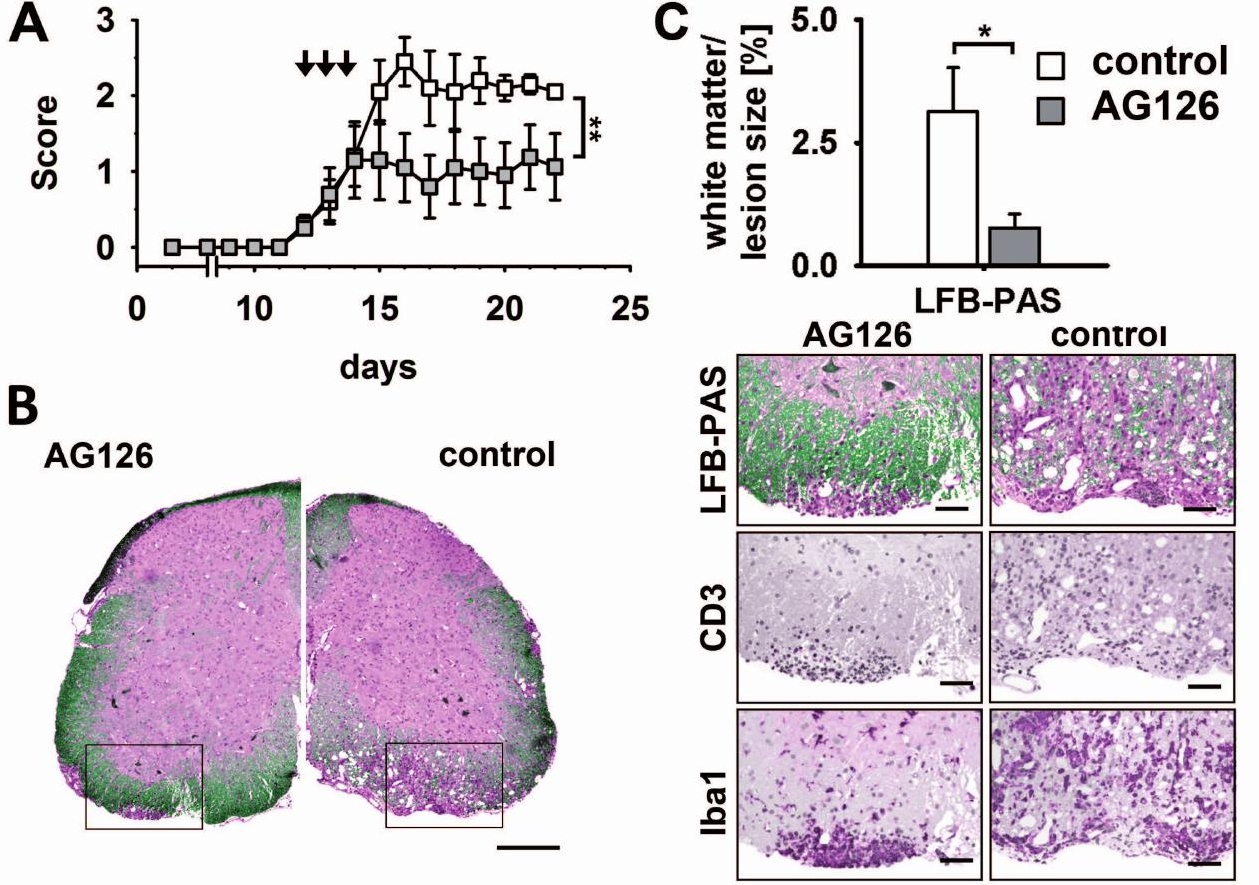


\%

- control

- AG126
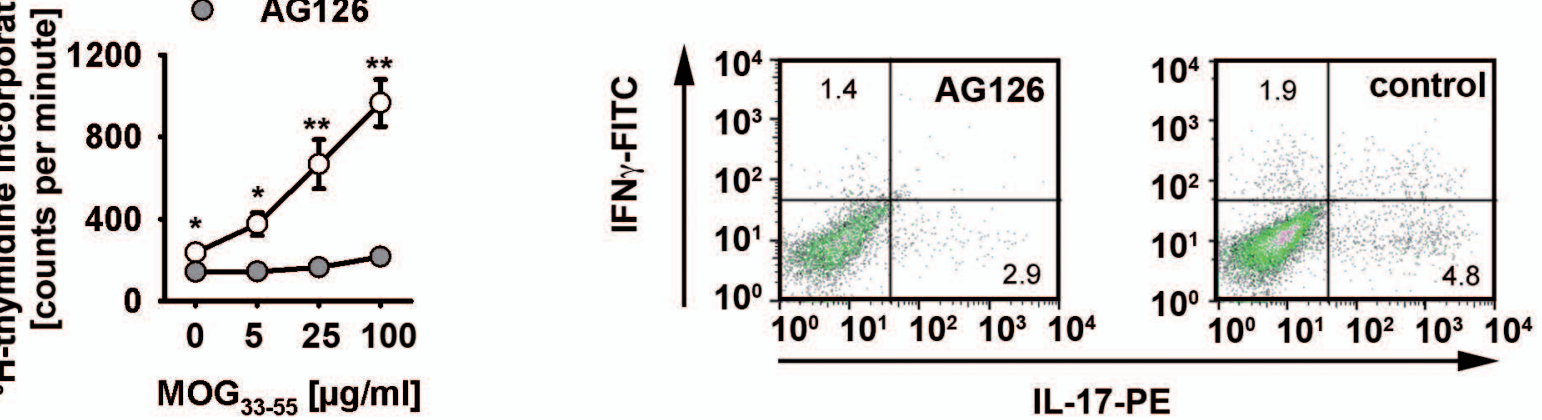

B

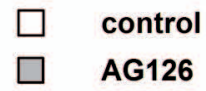

D

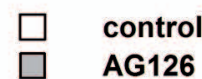

$\square \quad \mathrm{MOG}_{33-55} \mathrm{O}[\mathrm{\mu g} / \mathrm{ml}]$

$\square \quad \mathrm{MOG}_{33-55} 100[\mu \mathrm{g} / \mathrm{ml}]$
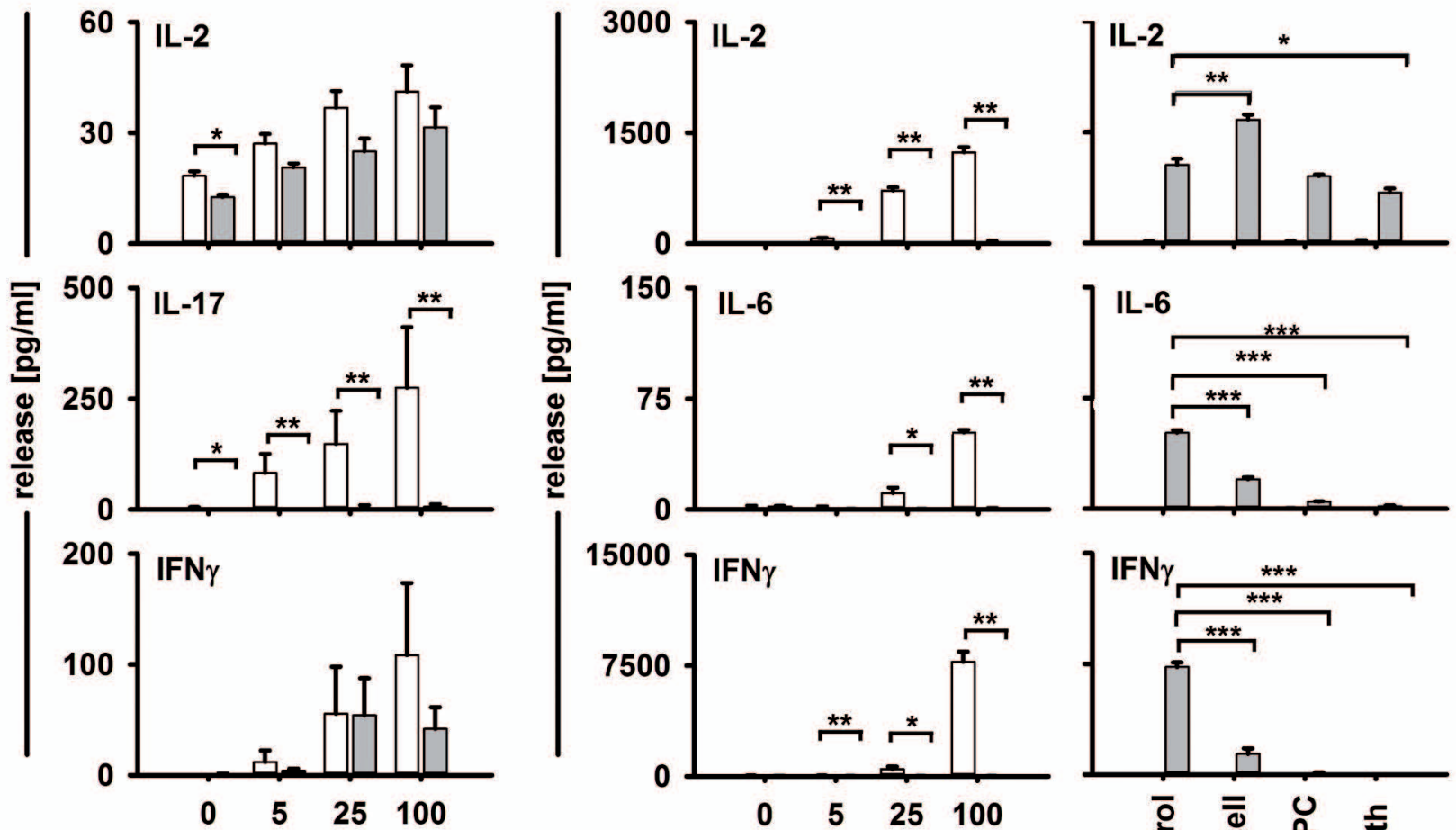

MOG33-55 [ $\mu \mathrm{g} / \mathrm{ml}]$

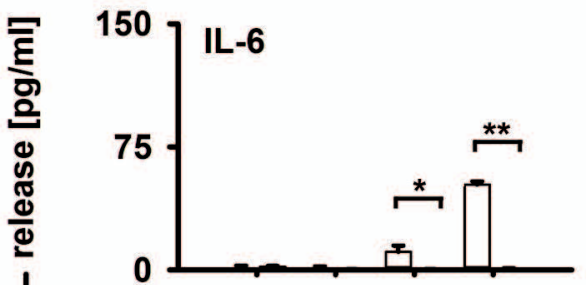

IL-6
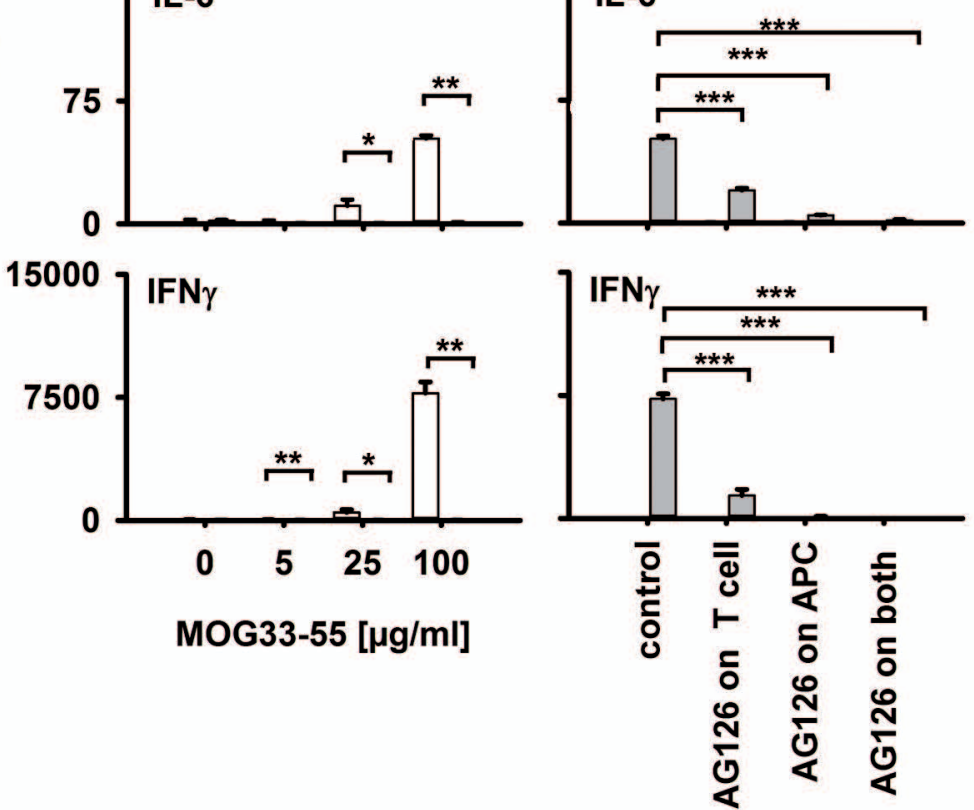
$\begin{array}{ll}\text { A } & \text { B }\end{array}$
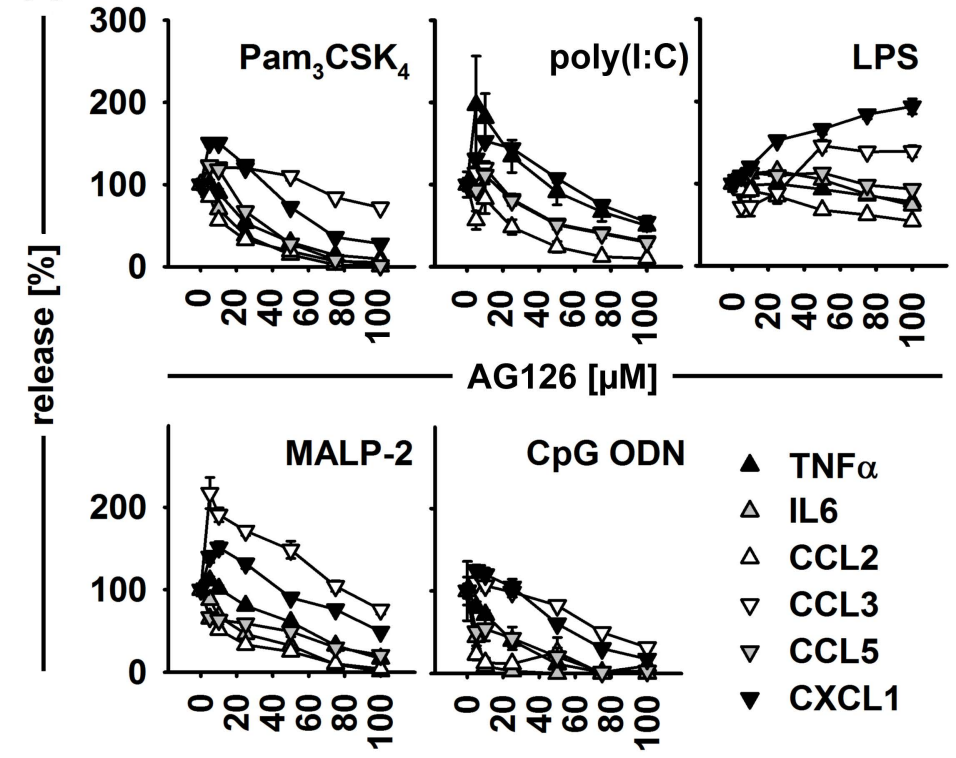

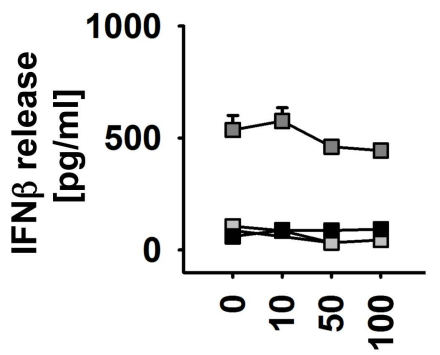

medium

․ $\mathrm{Pam}_{3} \mathrm{CSK}_{4}$

- LPS

- MALP-2

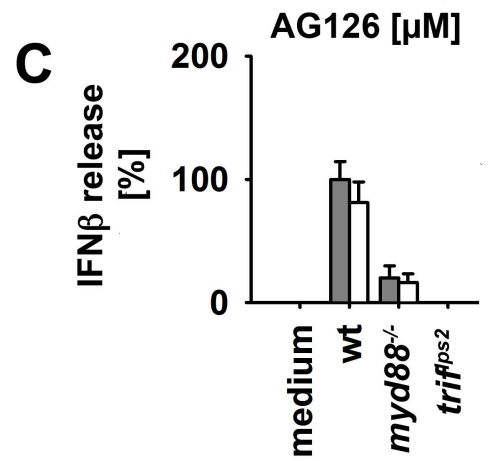

LPS

$\square$ LPS + AG126 


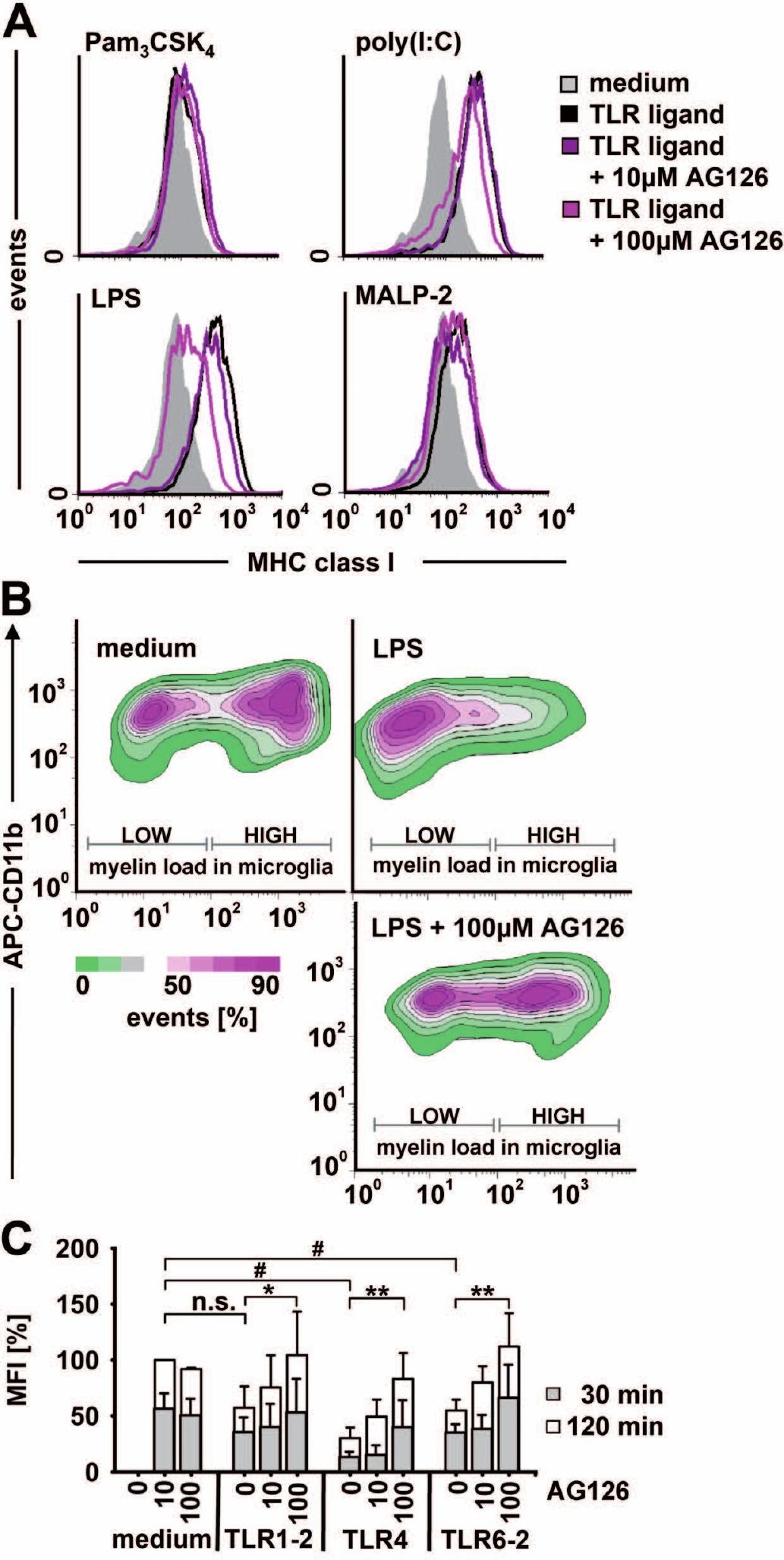


$\Delta$

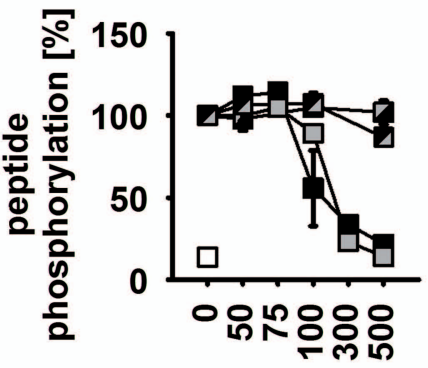

inhibitor $[\mu \mathrm{M}]$ $\square$ no BTK

- LFM-A13

口 AG126

- MN

$\square \mathrm{BZ}$
AG126

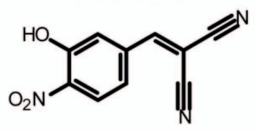

B

$$
-++++-++ \text { + BCR stim. }
$$

175kDa

$175 \mathrm{kDa}$

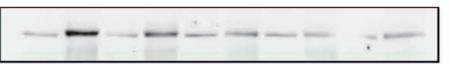

$\alpha$-phospho-PLC $\gamma 2$ (Y759)

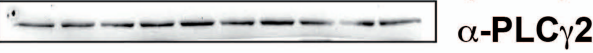

$$
\begin{array}{lll}
--++-+++-+ & \text { AG126 } \\
\frac{-}{\mathrm{CTL}} \frac{-+++}{50 \mu \mathrm{M}} \frac{-+++}{300 \mu \mathrm{M}} & \text { LFM-A13 }
\end{array}
$$

C

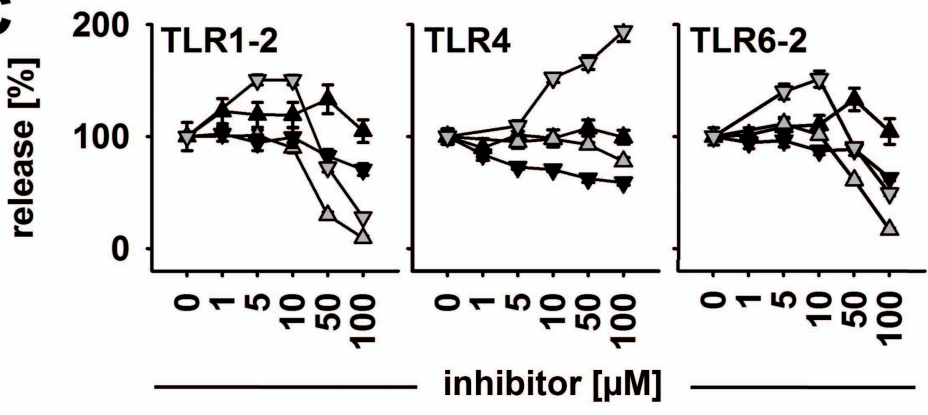
$\Delta$ LFM-A13
$\triangle$ AG126
TNF $\alpha$
v LFM-A13
$\nabla \quad A G 126$

CXCL1 
<smiles>N#CC(C#N)=Cc1ccc([N+](=O)[O-])c(O)c1</smiles>

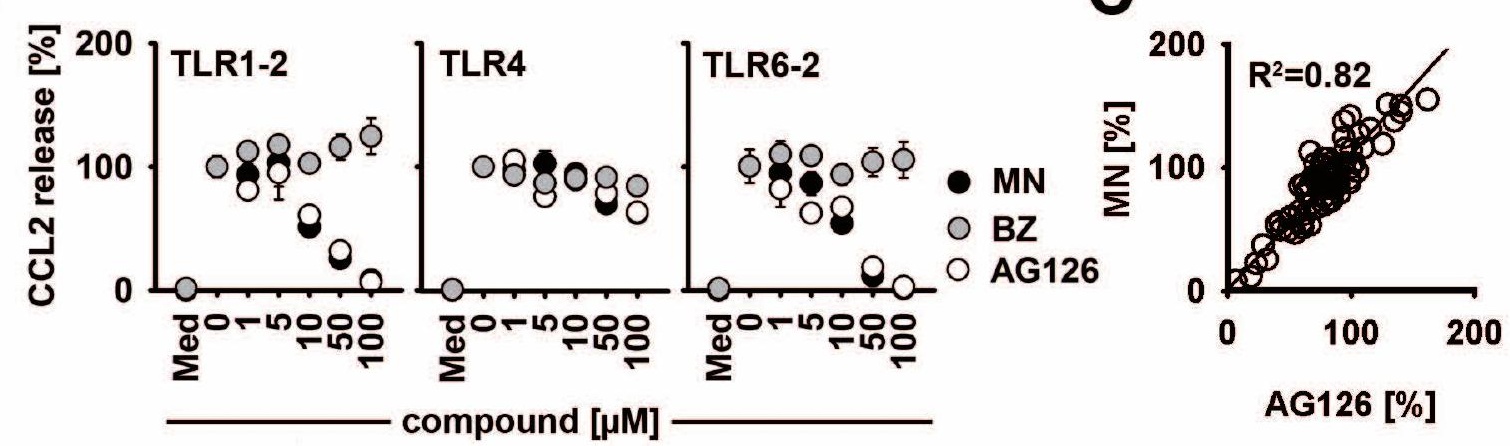


PAMPs S-LPS, Ra-

LPS, Rc-LPS, ReLPS...
CD14

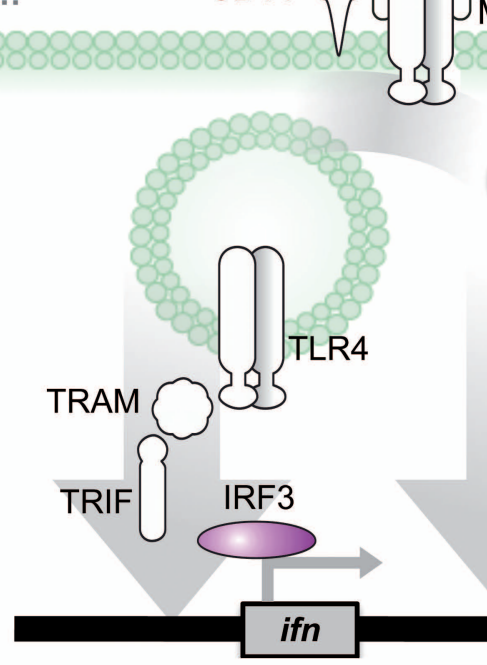

DAMPs fibronectin, fetuin, HMGB1, heparan, hsp, hyaluronan, S100A9 ... MD2
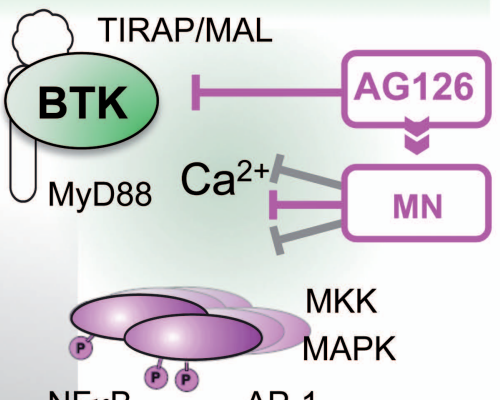
$\mathrm{NF}$ KB $\quad \mathrm{AP}-1$

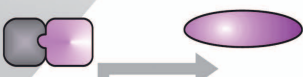

tnf
IFN $\beta$, TNF $\alpha$, CXCL1, CCL2, CCL3, CCL5 ...

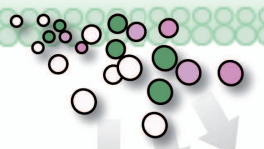

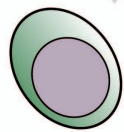

neutrophils

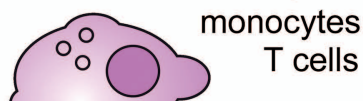



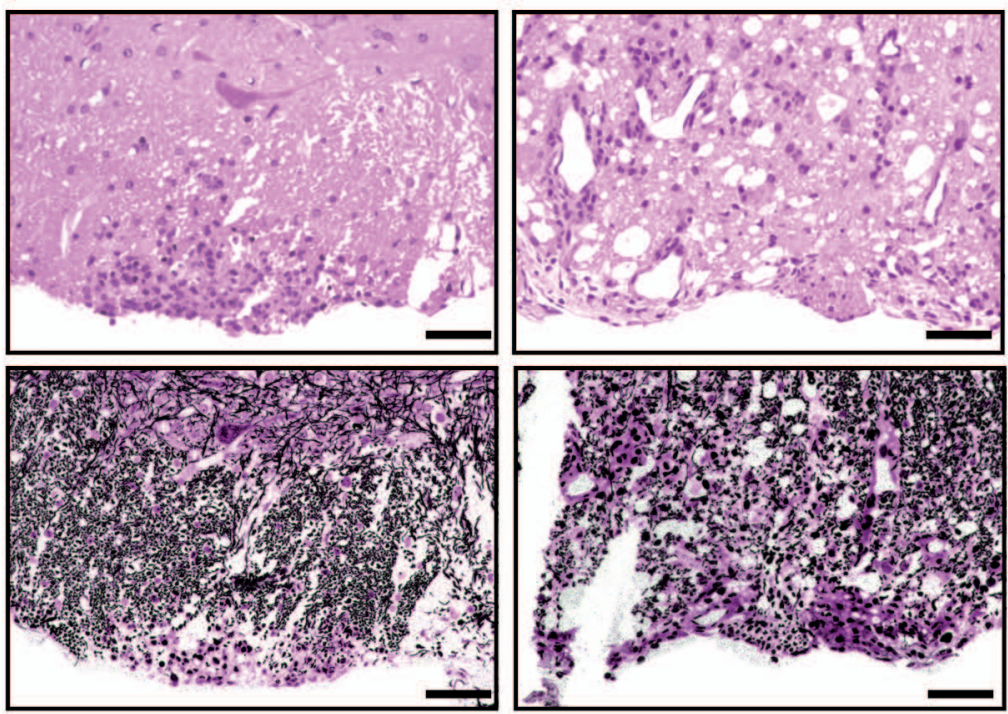

$\frac{\lambda}{0}$
$\frac{0}{3}$
$\frac{0}{0}$
$\frac{0}{0}$
$\frac{0}{0}$ 
B

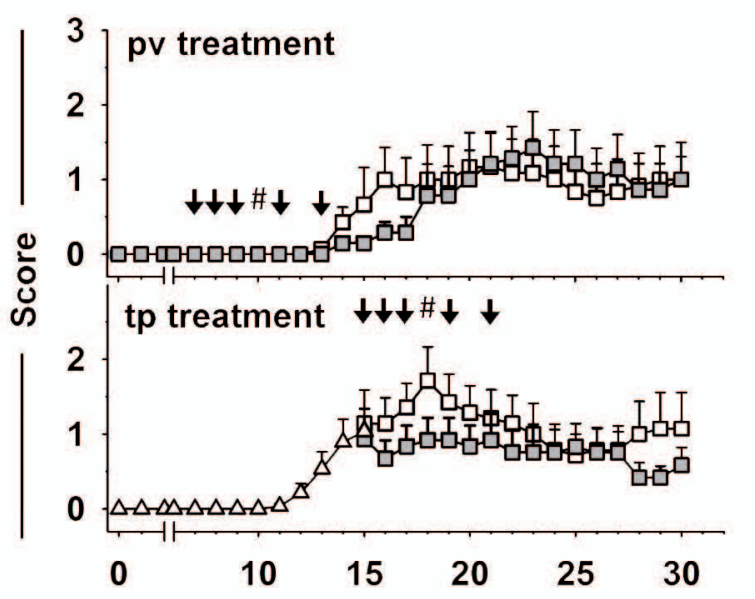

口 control

口 AG126

$\triangle$ untreated

pv treatment - control- AG126

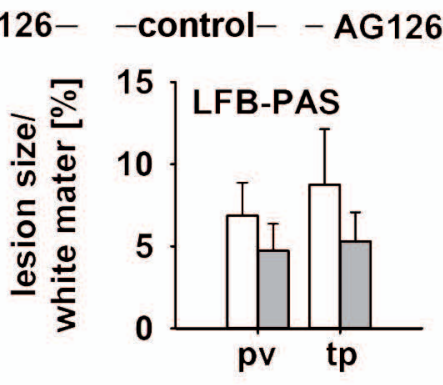

C

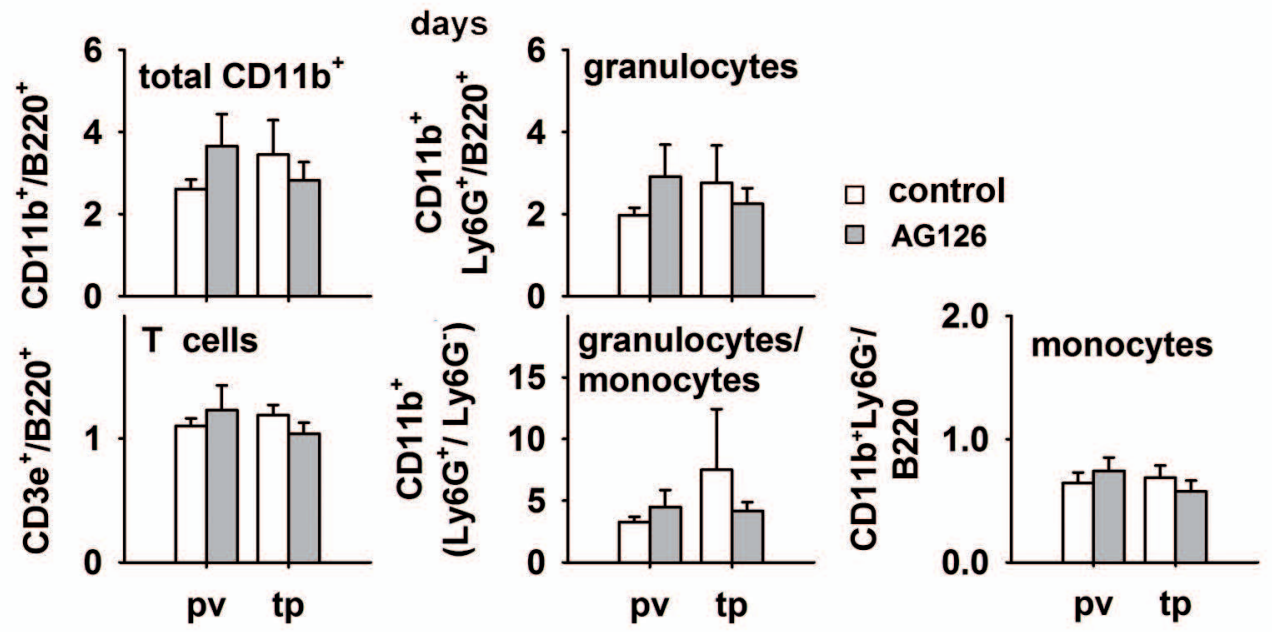



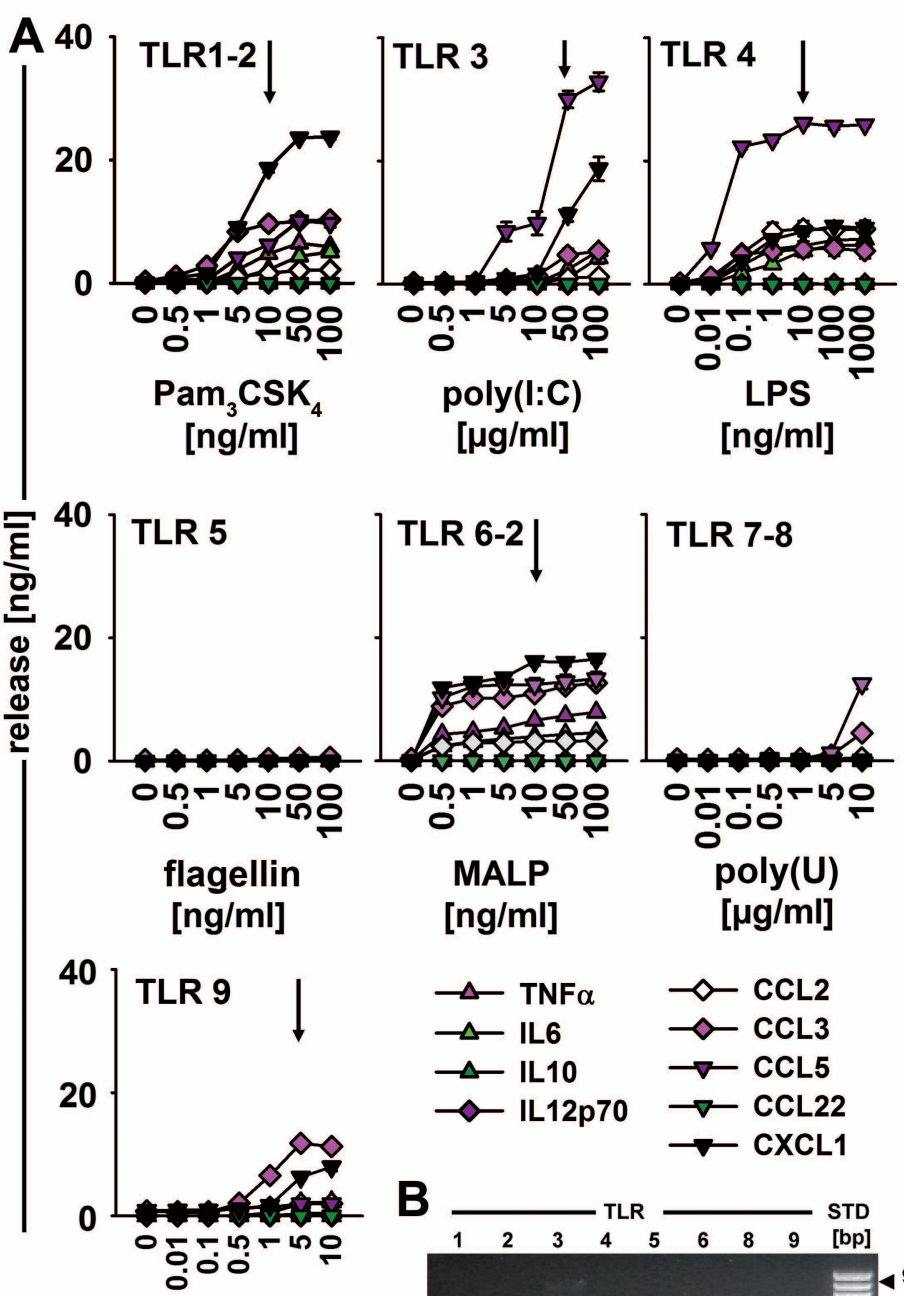

$\checkmark$ CCL2

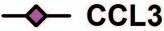

$\rightarrow-$ CCL5

$\rightarrow-$ CCL22

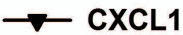

CpG ODN [ $\mu \mathrm{g} / \mathrm{ml}]$

B

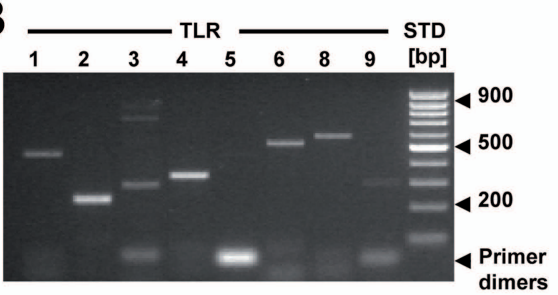




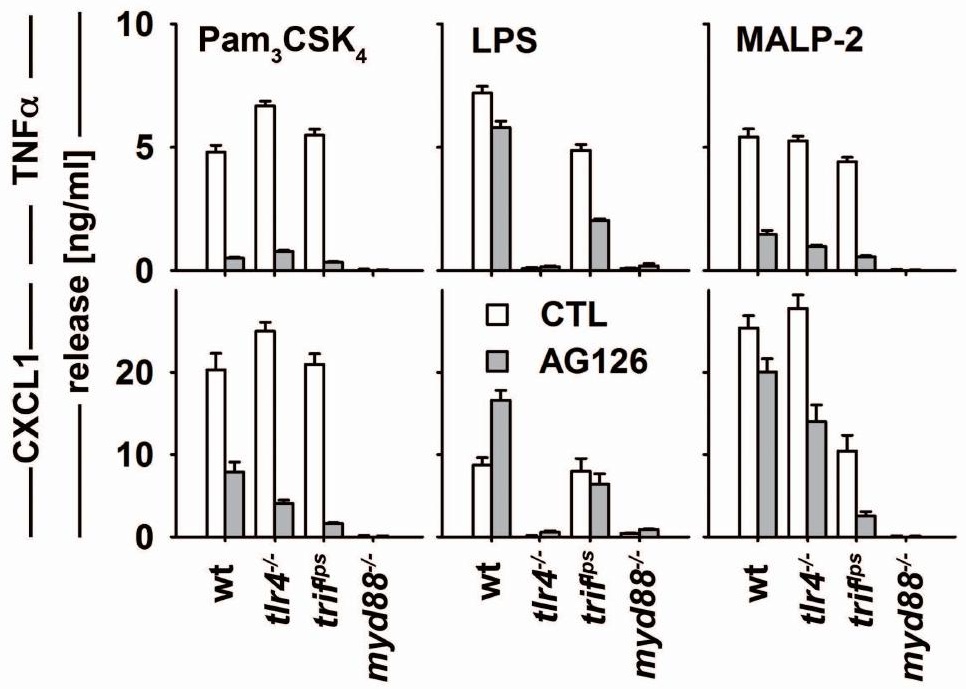




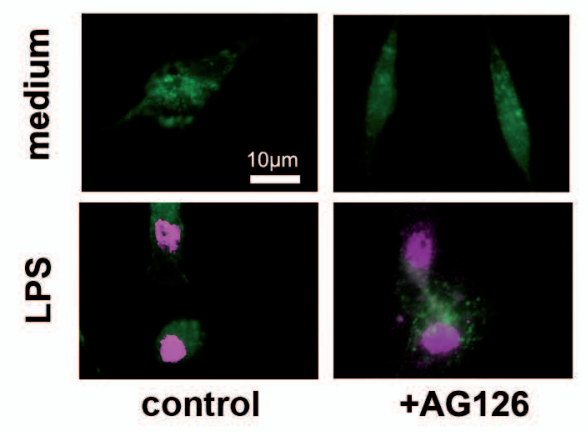

B

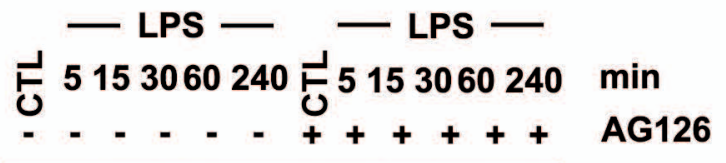

phosphoJNK total JNK

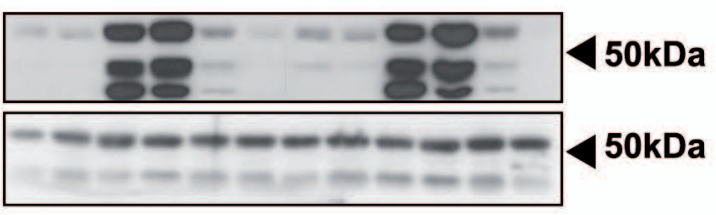

D

$\frac{5}{0}$
$\frac{0}{2}$
$\frac{\pi}{2}$
$\frac{0}{2}$
$\frac{0}{2}$
$\frac{0}{0}$
$\frac{0}{2}$
$\frac{0}{2}$

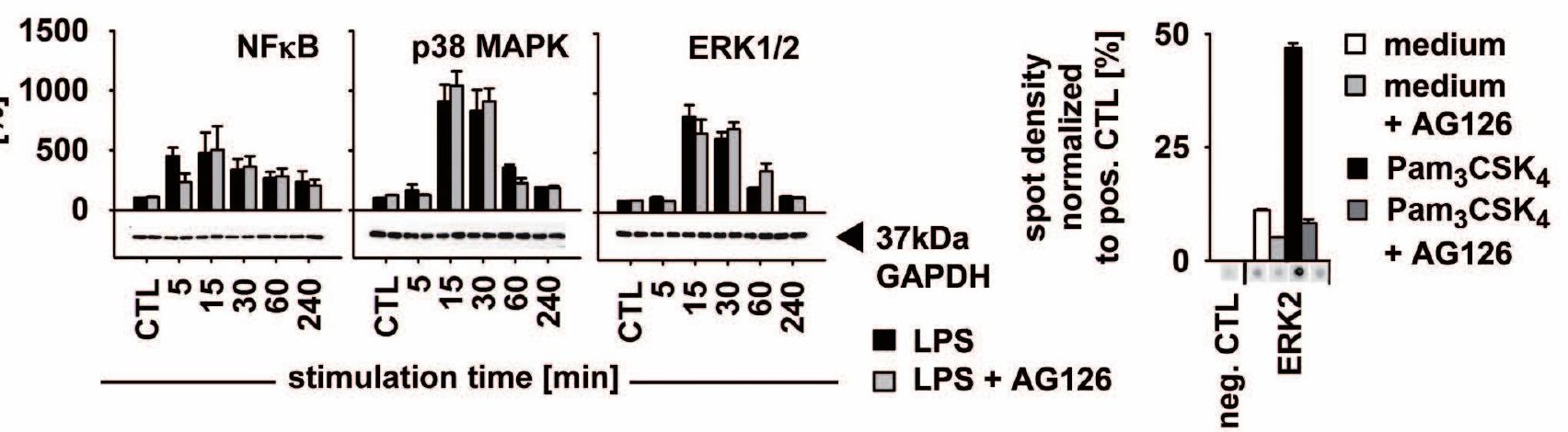




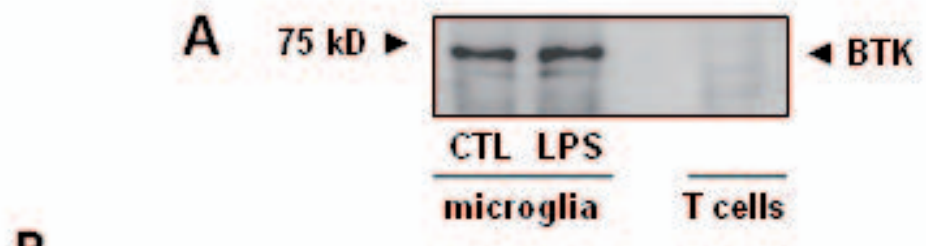

medium

LPS

DAPI

DAPI
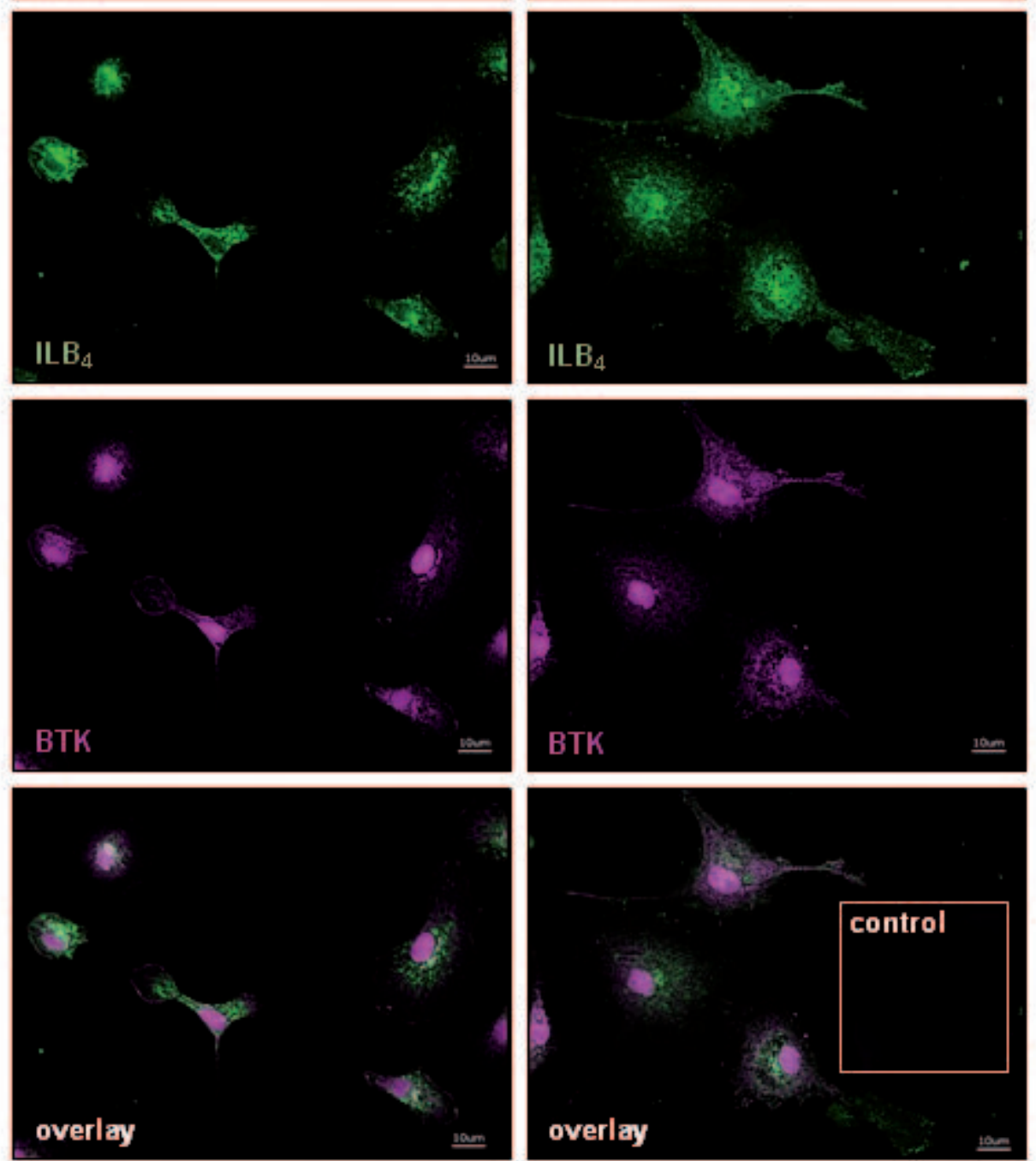
호 200

인

ธ

ป் 100

웜

valinomycin

$$
\text { AG126 -- }
$$

TLR ligand

medium $\mathrm{Pam}_{3} \mathrm{CSK}_{4} \mid$

LPS

MALP 


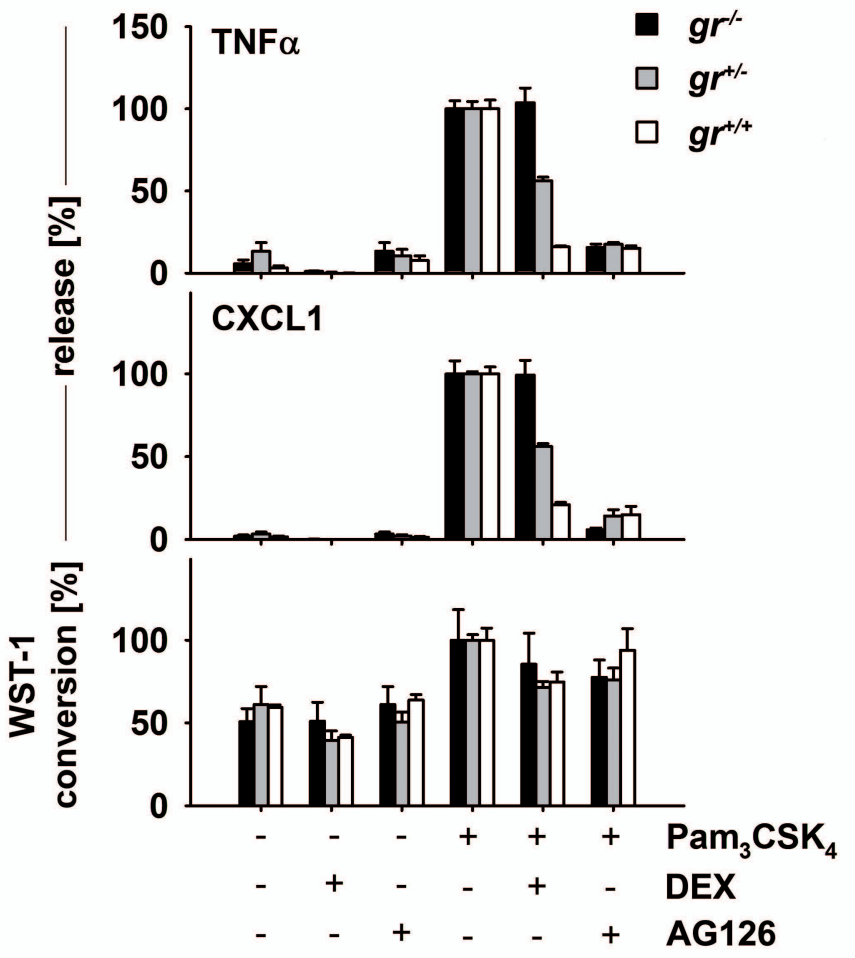



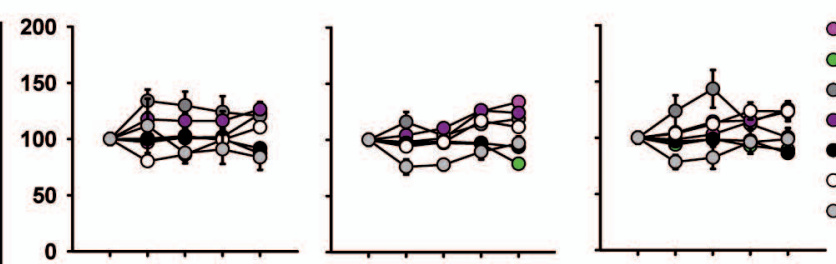

- $T N F \alpha$

B
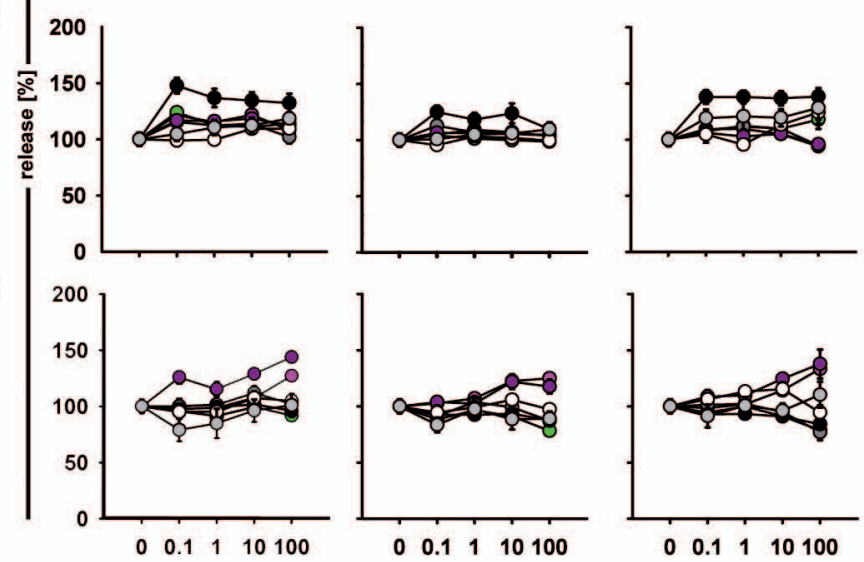

COX1 inhibitor [nM]

COX2 inhibitor [nM] COX1 \& COX2 inhibitor [nM] 
A

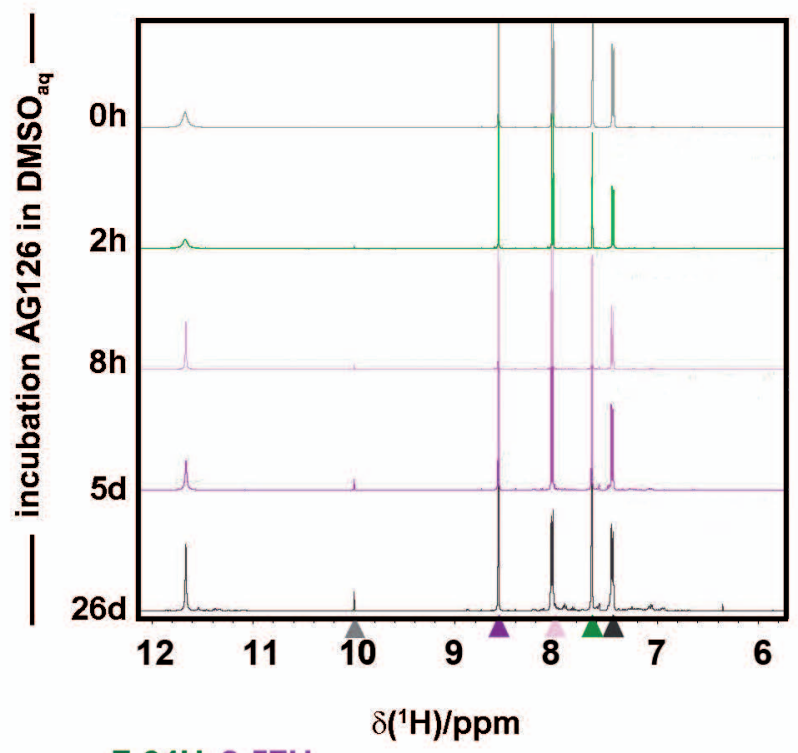

B

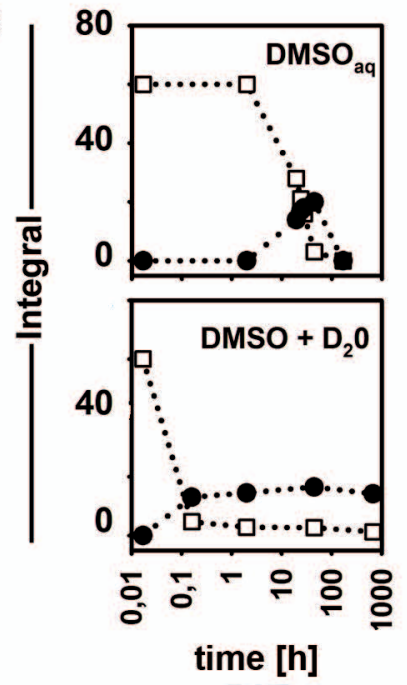

C

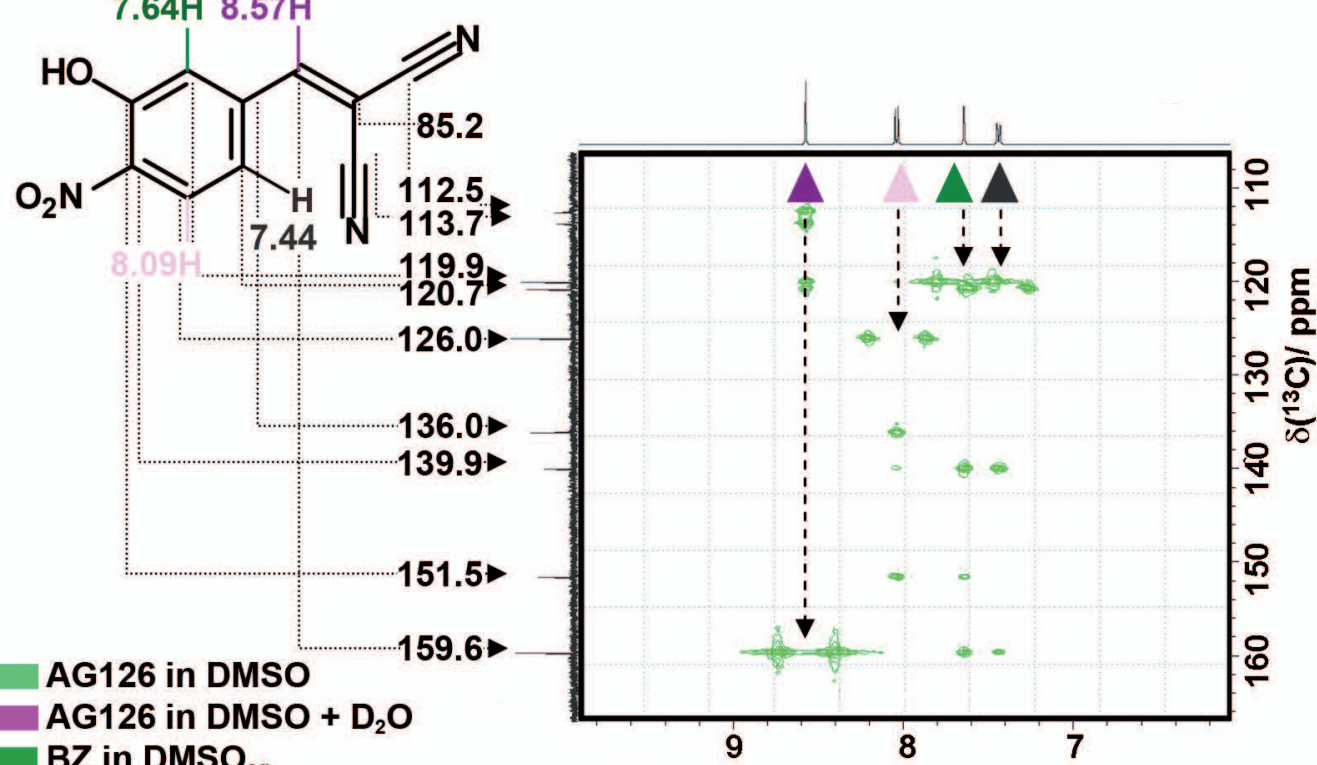

D

$\mathrm{BZ}$ in $\mathrm{DMSO}_{\mathrm{aq}}$

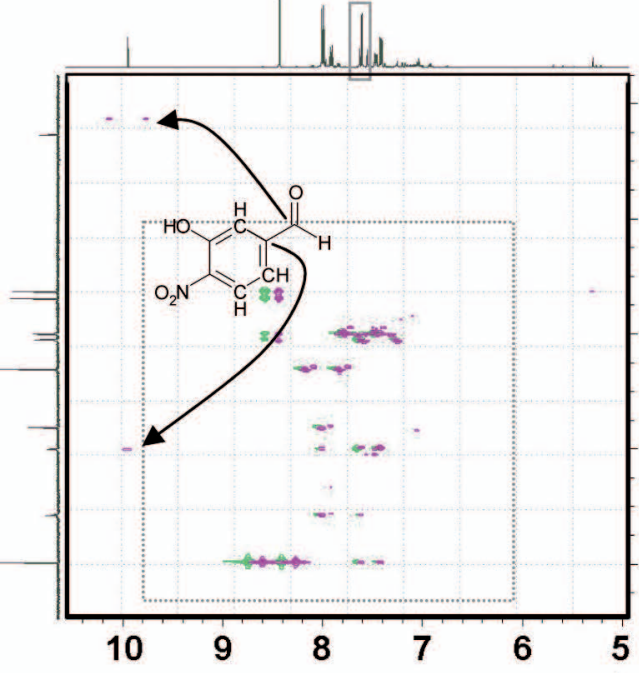

E

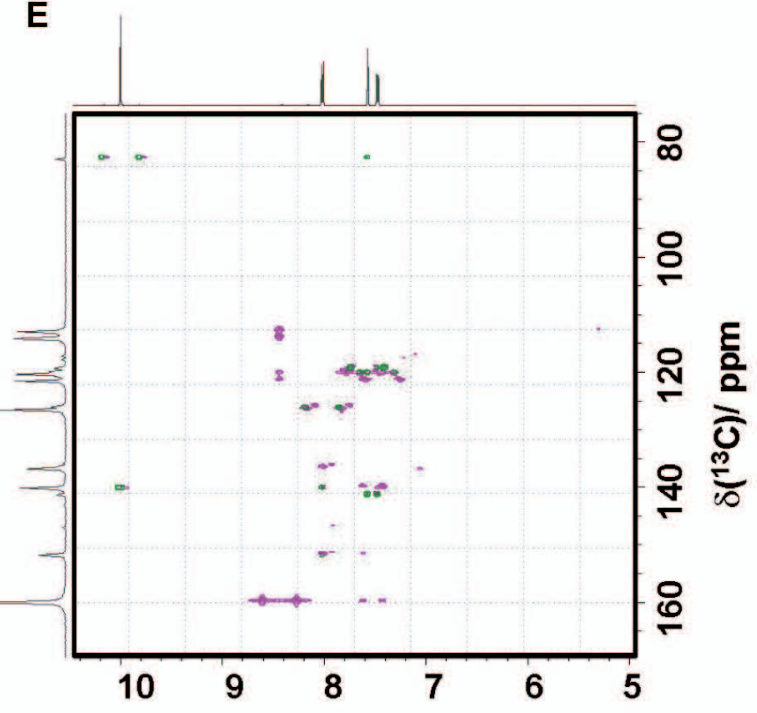



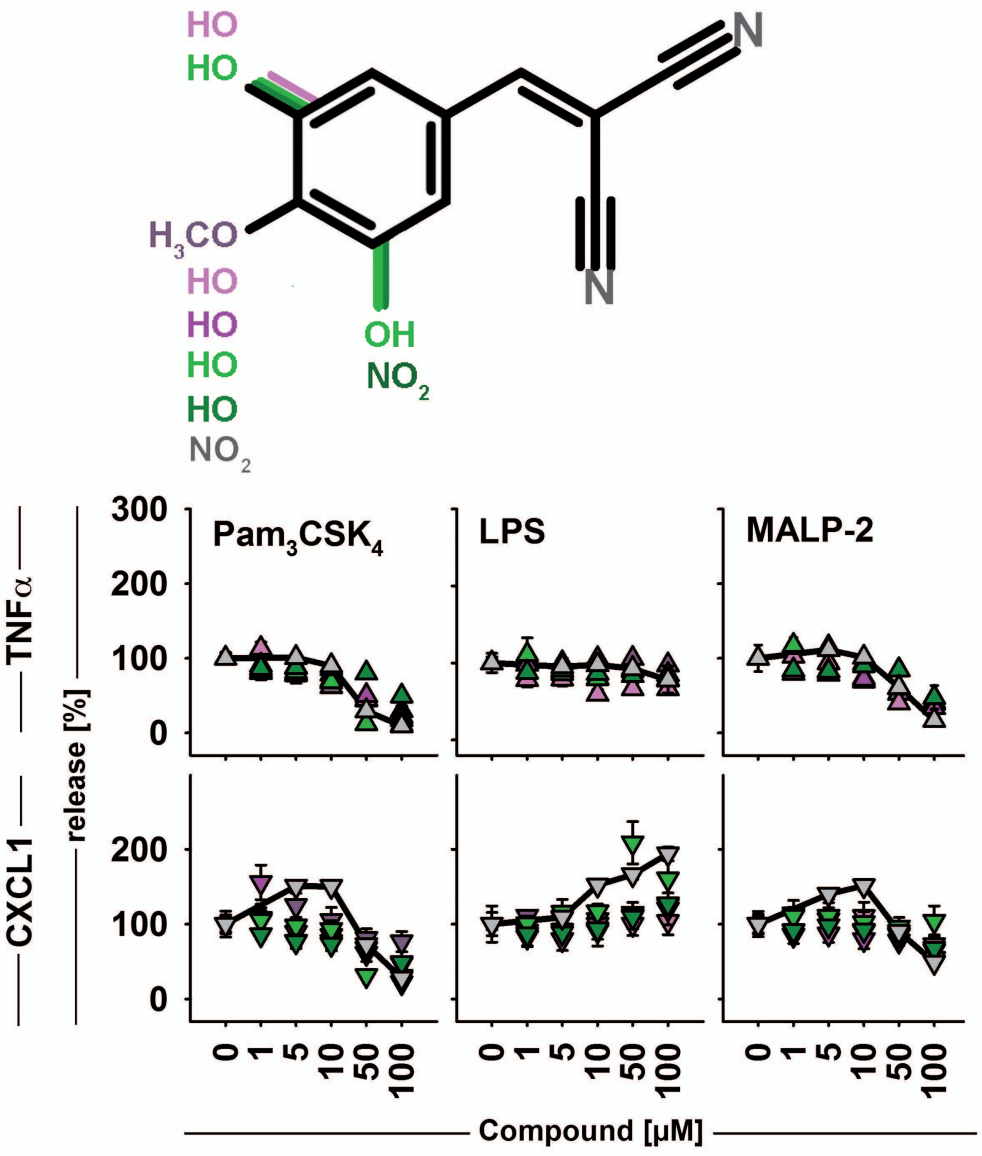

$\prec$ AG9 $\prec$ AG43 $\prec$ AG1288 $\prec$ AG18 $\prec$ AG82 $\prec$ AG126 